\title{
Rolling Contact Fatigue of Ceramics
}

\author{
Andrew A. Wereszczak, ${ }^{1}$ W. Wang, ${ }^{2}$ Y. Wang, ${ }^{2}$ M. Hadfield, ${ }^{2}$ \\ W. Kanematsu, ${ }^{3}$ T. P. Kirkland, ${ }^{1}$ and O. M. Jadaan ${ }^{4}$
}

${ }^{1}$ Oak Ridge National Laboratory, Oak Ridge, TN, USA

${ }^{2}$ Bournemouth University, Bournemouth, UK

${ }^{3}$ National Institute of Advanced Industrial Science and Technology, Japan

${ }^{4}$ University of Wisconsin-Platteville, Platteville, WI, USA

25 August 2006 
Page

Executive Summary _.................... ii

List of Figures $\ldots$

1. Introduction 1

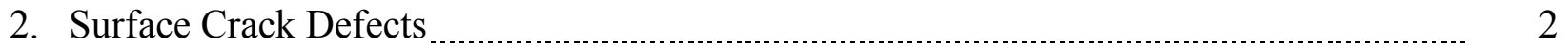

3. Fatigue Crack Propagation in Rolling Contact _ 5

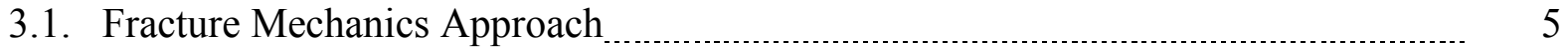

3.2. Crack Propagation Testing $\quad 6$

4. Rolling Contact Fatigue Testing

4.1. The Modified Four-Ball Machine/Five-Ball Machine $\quad 8$

4.2. Ball-on-Plate (Ball-on-Flat) Machine _ _ $\quad 10$

4.3. Ball-on-Rod Machine $\quad 11$

4.4. Disc-on-Rod Machine ….................................................................................. 14

4.5. Contacting Ring (Cylinder-on-Cylinder) Machine _ 15

5. Failure Modes of Rolling Contact Fatigue _...................................................... 16

5.1. Spalling Fatigue Failure 16

5.2. Delamination Failure _......................................................................... 22

5.3. Rolling Contact Wear _ 24

6. Development in Characterization Techniques of RCF Specimens _.............................. 25

6.1. Destructive Evaluation 26

6.1.1. Sphere Compression _............................................................................ 26

6.1.2. The C-Sphere Flexure Strength Specimen _ 27

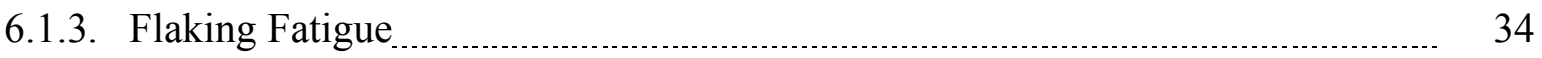

6.2. Non-destructive Evaluation $\quad 35$

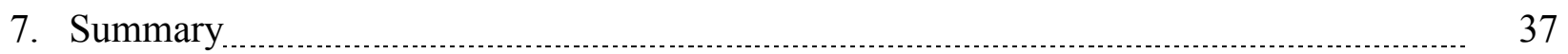

$\begin{array}{ll}\text { Acknowledgements } & 37\end{array}$

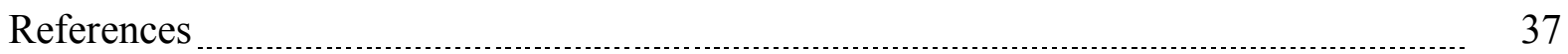




\section{Executive Summary}

High hardness, low coefficient of thermal expansion and high temperature capability are properties also suited to rolling element materials. Silicon nitride $\left(\mathrm{Si}_{3} \mathrm{~N}_{4}\right)$ has been found to have a good combination of properties suitable for these applications. However, much is still not known about rolling contact fatigue (RCF) behavior, which is fundamental information to assess the lifetime of the material. Additionally, there are several test techniques that are employed internationally whose measured RCF performances are often irreconcilable. Due to the lack of such information, some concern for the reliability of ceramic bearings still remains.

This report surveys a variety of topics pertaining to RCF. Surface defects (cracks) in $\mathrm{Si}_{3} \mathrm{~N}_{4}$ and their propagation during RCF are discussed. Five methods to measure RCF are then briefly overviewed. Spalling, delamination, and rolling contact wear are discussed. Lastly, methods to destructively (e.g., C-sphere flexure strength testing) and non-destructively identify potential RCF-limiting flaws in $\mathrm{Si}_{3} \mathrm{~N}_{4}$ balls are described. 


\section{LIST OF FIGURES}

Figure

$\underline{\text { Page }}$

1 Typical crack defects found on ceramic ball surfaces under UV light.

(a) Star defect, (b) pressing defect, (c) single ring crack, and

(d) concentric ring cracks.

2 Loading configuration of four-ball machine.

3 Loading configuration of five-ball machine.

4 Loading configuration of ball-on-plate machine.

5 Loading configuration of ball-on-rod machine.

6 Japanese type ball-on-rod machine.

7 Loading configuration of disc-on-rod machine.

8 Contacting ring (cylinder on cylinder) machine.

9 Schematic illustration of the process of rolling contact failure in ceramics and metals.

10 Spalling fatigue failure resulting from artificially induced ring /cone cracks (SEM micrographs). (a) Single spall and (b) double spall.

11 Loading configuration and ring crack location on the contact track.

(a) Loading system. (b) Geometric location on the contact track.

(c) Twelve typical locations within the contact path.

12 Surface fatigue damage resulting from 'natural' ring cracks (Figs. 10(a)-(c)) and line defects (Fig. 10(d)). (a) Ring cracks and wear track after 113 million stress cycles at crack location $\beta=0^{\circ}$ and $\delta=0$ (optical micrograph). (b) Incipient failure after 27 million stress cycles at the crack location $\beta=45^{\circ}$ and $\delta=0$ (optical micrograph). (c) Spall SEM micrograph after 16 million stress cycles at crack location $\beta=90^{\circ}$ and $\delta=0$. (d) Spall SEM micrograph after 1.4 million stress cycles at $\beta=90^{\circ}$.

13 Subsurface observation of spalling fatigue failure (optical micrograph).

14 Surface damage resulting from ceramic/steel contact (SEM micrographs). (a) Lateral crack spall. (b) Radial crack propagation and (c) delamination and (d) Ceramic/ceramic contact at high Hertz contact pressure.

15 Relationship between crushing strength and life ratio.

16 Schematic of the 12.7-mm-diameter C-sphere flexure strength specimen.

17 Diametral compression of the $\mathrm{C}$-sphere flexure specimen causes fracture initiation from a hoop stress at the outer fiber.

18 Nodal first principal stress distribution (left) and element $1^{\text {st }}$ Principal stress distribution (right) for the 12.7-mm-diameter C-sphere specimen.

19 Maximum $1^{\text {st }}$ Principal tensile stress (located at outer fiber - see Fig. 17) as a function of diametral compressive load for the $12.7 \mathrm{~mm}$-diameter Csphere geometry in Fig. 16 for a $\mathrm{Si}_{3} \mathrm{~N}_{4}$. 
$20 \mathrm{Si}_{3} \mathrm{~N}_{4} 12.7 \mathrm{~mm}$-diameter C-sphere flexure strength specimens.

21 BS-SEM microstructure on finished ball surfaces of NBD200 and SN101C.

22 C-sphere Weibull strength distribution comparison of NBD200 and SN101C.

23 95\% confidence ratio rings for NBD200 and SN101C C-sphere strengths.

24 Example of a surface-located strength-limiting flaw in a SN101C $\mathrm{C}$-sphere flexure strength specimen. This specimen had a strength of $770 \mathrm{MPa}$.

25 Weibull plots of rolling contact fatigue lifetime.

26 Elastic properties of NBD200 and SN101C balls measured using Resonance Ultrasound Spectroscopy. 


\section{Introduction}

Technical ceramics used as materials for rolling contact bearing components show some practical advantages over traditional bearing steels. The properties of ceramics, specifically low density and high stiffness, are of most interest to gas turbine [1] and machine tool manufacturers [2]. High hardness, low coefficient of thermal expansion and high temperature capability are properties also suited to rolling element materials. Silicon nitride $\left(\mathrm{Si}_{3} \mathrm{~N}_{4}\right)$ has been found to have a good combination of properties suitable for these applications. Research over the past three decades on structure, quality control and manufacturing techniques has produced ceramic materials that are suitable alternative to steel for rolling contact bearing design. This is especially true for hybrid ball bearings, i.e. precision angular contact ball bearings using ceramic rolling elements are now offered as standard components with in the ball bearing manufacturing industry.

An expansion in the use of ceramic bearings necessitates guidelines for the choice of bearings or rolling elements. In light of these requirements, ASTM standard F2094-01, "Standard Specification of Silicon Nitride Bearing Balls," has been issued recently. The dimensional specifications of balls are based on those of rolling element bearing steel balls. The most remarkable thing in the standard is that the ranking of $\mathrm{Si}_{3} \mathrm{~N}_{4}$ 's mechanical properties is provided depending on various applications of bearings. However, nothing is described about rolling contact fatigue (RCF) behavior, which is fundamental information to assess the lifetime of the material. Due to the lack of such information, some concern for the reliability of ceramic bearings still remains.

Rolling contact fatigue (RCF) is the surface damage process due to the repeated application of stresses when the surfaces of two bodies roll on each other. Rolling contact fatigue is encountered most often in rolling element bearings and gears. The failure process of rolling contact fatigue involves fatigue crack initiation and propagation, which is related to the characteristics of the surface quality, stress distributions and lubrication condition. Surface crack defects are considered as a main factor that causes rolling contact fatigue failure at the present. It is difficult to detect these surface cracks during high volume production processes and hence it is 
crucially important to understand their influence and the fundamental mechanism of the failures they cause.

\section{Surface Crack Defects}

Surface cracks caused by manufacturing pressing faults or blunt impact loads are the most common types found on ceramic ball surfaces. Typical images of the crack defects found on the ceramic ball surface are illustrated in Fig. 1. Most of the defects are ring cracks. Lateral and radial surface cracks are less common and occur due to poor sintering mixture or a sharp indention load. Surface ring cracks are circular extending for approximately $1 / 4$ to $1 / 3$ of the circumference of a circle. These circular cracks have been studied extensively. The fundamental basis for an explanation of the ring and cone fracture is provided by the Hertz theory of elastic contact. Traditionally, Hertzian cone cracks have been most widely studied in flat silicate glass plate, using spheres of hard steel or tungsten carbide. Extension to ceramics is becoming more prevalent and the theory of Hertzian fracture has been significantly developed during recent years [3]. A typical experiment involves pressing an indenter into the surface of the solid with a progressively increasing load and observing the pattern of fracture which develops under the contact. Under a blunt indent, a well-defined cone shaped crack pops in when the normal load reaches a critical magnitude [4-5]. The surface tensile stress for ring cracking being visible is much greater than that required for fracture in bulk tensile test specimens. This has been attributed to the small volume acted upon by the contact-induced tensile stress. 


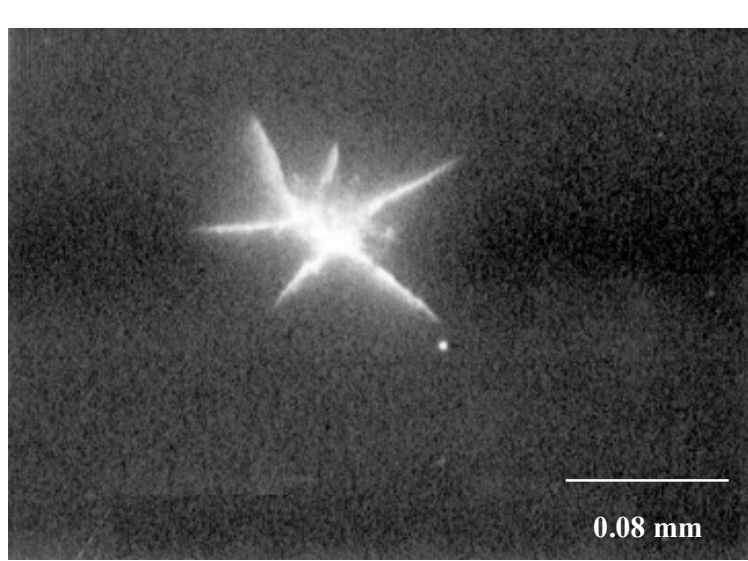

(a)

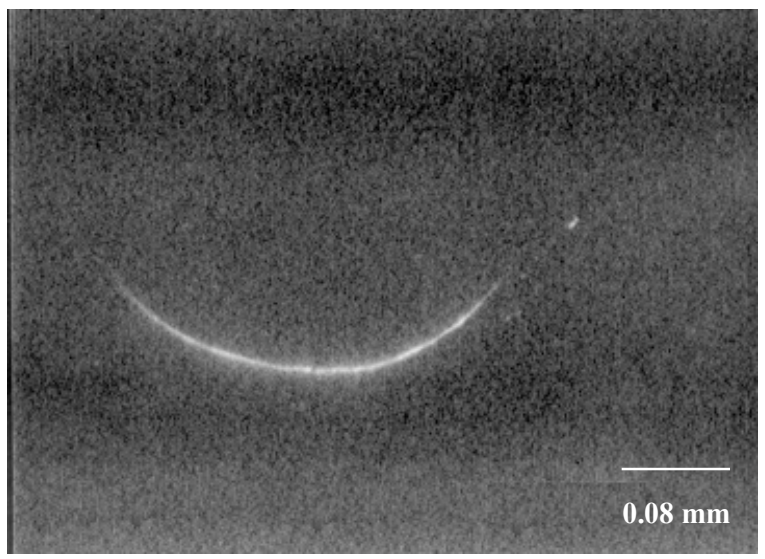

(c)

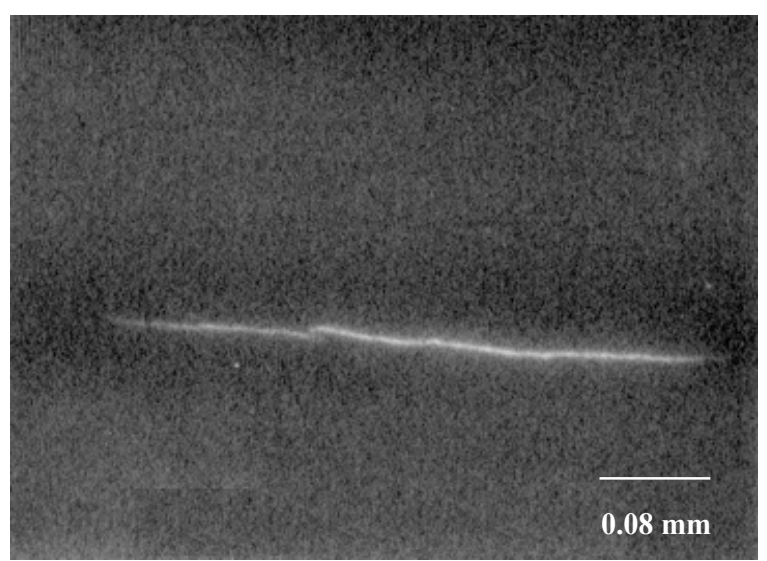

(b)

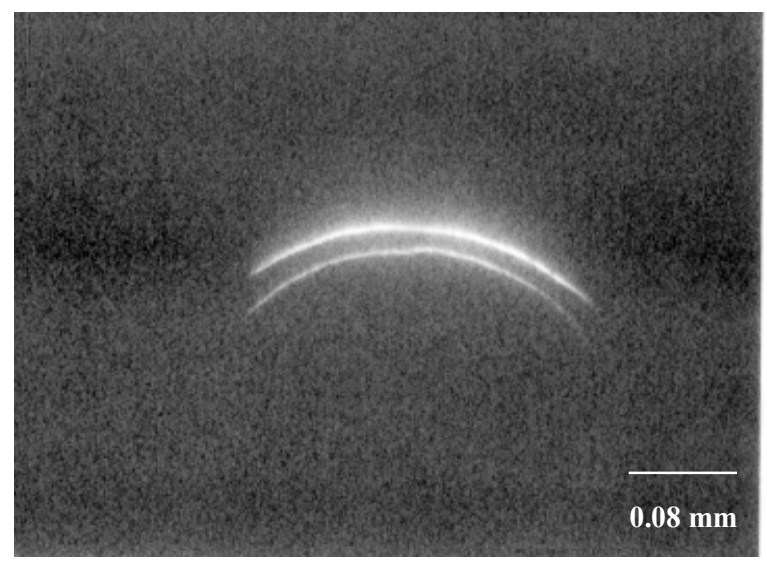

(d)

Figure 1. Typical crack defects found on ceramic ball surfaces under UV light. (a) Star defect, (b) pressing defect, (c) single ring crack, and (d) concentric ring cracks.

Ring crack initiation load of HIP $\mathrm{Si}_{3} \mathrm{~N}_{4}$ bearing balls was experimentally studied by some researchers [6-7]. Initiation of a ring crack was detected using acoustic emission. The ring crack initiation load showed considerable scatter and ranged from 3 to $6 \mathrm{KN}$ (corresponding to maximum Hertz contact pressures of 14 and $18 \mathrm{GPa}$ ). The ring crack initiation load is much smaller than the crushing load and has been shown to approximately follow two-parameter Weibull distribution with a shape parameter ranging from 9 to 11. Impact cracking of $\mathrm{Si}_{3} \mathrm{~N}_{4}$ balls, during ball finishing or by subsequent handling, is a cause for concern since a surface crack is the type of defect most likely to cause failure in a hybrid rolling element bearing. Ring 
cracks formed prior to, or during, the final lapping or polishing stage are particularly difficult to detect. Such cracks are not visible with optical techniques even at high magnifications except after processing with high sensitivity fluorescent penetrants. Impact cracking of $\mathrm{Si}_{3} \mathrm{~N}_{4}$ balls was investigated by Cundill [8], leading to a parameter for assessing impact resistance. Some materials types were found to be more resistant to impact cracks than others. The types of $\mathrm{Si}_{3} \mathrm{~N}_{4}$ densified by sintering, followed by hot isostatic pressing and by gas pressure sintering, have the best impact resistance. For a ball size of $6.35 \mathrm{~mm}$, the maximum contact pressure of 20-25 GPa was required to form surface ring cracks; for ball sizes of $12.7 \mathrm{~mm}, 10-15 \mathrm{GPa}$ was required; for ball sizes of more than $20 \mathrm{~mm}, 10-12 \mathrm{GPa}$ was required.

A number of theoretical models have been developed to predict both the fracture load and the subsequent length of the cracks [9-11]. Frank and Lawn [9] investigated the development of the cone crack from the ring crack in the strongly inhomogeneous Hertzian stress field. Mode I Stress intensity factor at the cone crack front was calculated by modelling it as a twodimensional plane strain crack in an infinite medium loaded by the stresses acting on the location of the cone crack in the corresponding uncracked body. It was assumed that the inclined sides of the cone crack followed trajectories of the minimum principal stress so that it was perpendicular to the maximum principal stress. This model predicts that the crack propagation arrests at a depth which is related to the applied load. The partial cone cracks can be generated if the indenter slides over the surface under the action of a combined normal and tangential load. The cracks are initiated at the trailing edge of the contact, and propagate almost perpendicular to the surface and perpendicular to Mode I tensile loading [12-13].

Warren [14] used a similar two-dimensional approximation and considered the effect of ring crack initiation some distance outside of the circle of contact. The model was combined with experiments to measure the fracture toughness of carbides based on the initiation of the ring crack. Mouginot and Maugis [11] also used the two-dimensional approximation to analyze cracks generated by both spheres and flat punches. Li and Hills [15] fully analyzed circular crack initiation and propagation using a numerical calculation method. A finite element method was used. They found that the Mode II stress intensity factor was about one-tenth of the Mode I stress intensity factor. A review paper by Warren [16] discussed ring crack initiation and 
propagation using analytical techniques. The first two stages of surface defect growth show that surface flaws develop into complete rings. In the final phase the crack develops into a cone.

\section{Fatigue Crack Propagation in Rolling Contact}

\subsection{Fracture Mechanics Approach}

Fatigue crack propagation is always involved in rolling contact fatigue failure. Many efforts have been completed to relate crack propagation behavior with RCF life performance since Suh [17] published delamination wear theory. The bulk of that research was focused on the experimental aspects of wear. Only a few attempts have been made to develop analytical models for predicting the rolling contact wear process. The importance of determining analytical models for wear mechanisms has been discussed [18]. Wear models must be described mechanistically to better understand how contact damage occurs and to develop formulae for materials removal by wear. Fracture mechanics has been applied to the analysis of wear modes in a number of studies. Numerous researchers [19-21] have presented a fracture mechanics approach to delamination wear of metals. They analysed a subsurface crack parallel to surface of a halfplane subjected to Hertzian surface load. The stress intensity factors at the crack tips were calculated from an approximate stress field induced by the contact load in a crack-free half plane. Keer and Bryant [22], Bryant et al. [23] analysed surface cracks at an angle to a surface acted on

by a Hertzian contact load. In Keer and Bryant, pressure from entrapped lubricant was considered as a crack opening force; in Bryant et al. sufficient lubrication was taken to exist in the crack such that the crack face friction was zero. The analyses were further extended in Miller et al. [24] to include the effects of subsurface inclusions and asperity perturbations on the pitting crack. Finally, Bower [25] thoroughly analysed the surface pitting crack, summarising the effects of crack face friction and lubrication pressures on crack propagation, and including loading history dependence when regimes of slip and stick were considered. In all of these analyses, Mode II stresses were the main cause of crack propagation. This caused crack propagation to be highly dependent on the coefficient of friction between the crack faces. 
Several attempts have been made to explain the wear mechanisms in brittle materials [18]. In the case of brittle materials, cracks may occur on the surface due to tension or subsurface cracks parallel to the contact path due to shear. Friction in rolling and sliding contact can arise from asperity interlocking, adhesion or abrasion by debris trapped between the contacting surface and viscous drag of the lubricant. A qualitative model was presented to describe the micro-chipping wear mode in ceramic rollers [26]. It is stated that micro-chipping cracks can form as a result of the stress distribution due to a Hertzian contact. Because the direction of principal stresses varies rapidly at an indentation contact, cracks propagating at the surface will link or branch to turn parallel to the surface, thus providing a mode for wear material removal. A strong dependence was seen relating the wear particle size with the coefficient of friction. Thomsen and Karihaloo [27] modelled near-surface cracks in zirconia ceramics which are subjected to contact loading. It is concluded that frictional contact may have a significant influence, especially upon the sliding mode (Mode II) deformation of the closed crack. In the analysis for a phase transforming material, the friction contact between the crack faces may even be of greater importance, since the transformation zones at the crack tip(s) showed a marked closing effect on the tips, thus exerting significant compressive stresses there. These compressive stresses would, in turn, induce frictional stresses opposing the sliding deformation of the crack tips.

\subsection{Crack Propagation Testing}

Fatigue crack propagation in ceramics has been studied in two modes: long crack and short crack studies. The long crack studies (typically for crack lengths $>\sim 500 \mu \mathrm{m}$ ) were done with through cracks in pre-cracked specimens, such as single-edge-notched specimens in three and four-point bending or tapered double-cantilever beam specimens, or compact tension specimens. Crack lengths were monitored optically or by measuring the resistance of a conducting coating. Linear elastic stress-intensity solutions for the various specimen geometries are given in standard handbooks [28]. Short crack experiments (crack lengths $<\sim 500 \mu \mathrm{m}$ ) were done by bending beams using surface cracks introduced from a notch or by indentation. Stress intensity factors for such surface cracks can be obtained from linear elastic solutions for three-dimensional semielliptical surface cracks in bending (and /or tension) [29]. The long crack propagation studies gave results that could be described by the Paris Law, but the exponent $m$ varied between 12 and 
40 , which is much larger than the values of 2-4 typical of metals. The short crack studies gave much greater crack growth rates than the long crack studies at equivalent applied stress intensity values. Also, the crack growth takes place in the short crack studies at stress intensities below the threshold value required in long crack studies [30].

Studies of cyclic fatigue in ceramics using long crack techniques are clearly important in understanding basic fatigue phenomena in ceramics and data obtained in such experiments may apply to design considerations in some circumstances. However, the same problem arises as with other uses of long crack data. Namely, ceramics having only the naturally occurring short cracks are generally used for load-bearing applications. Thus fatigue data for short cracks is needed. Results on small fatigue cracks in ceramics, however, are very limited. In contrast to long crack results, the small cracks grow at progressively decreasing growth rates with increase in size, until finally linking together as the density of cracks across the specimen surface increases; the specimen then fails. Small crack propagation rate display a negative, dependency on stress intensity and occur at applied stress intensity levels well below $\Delta \mathrm{K}_{\mathrm{th}}$.

Mechanisms of cyclic fatigue in ceramics have not yet been definitely established. The possible mechanisms have been classified into two categories: intrinsic and extrinsic [30-31]. The intrinsic mechanism would involve the creation of a fatigue-damaged microstructure ahead of the crack tip that would produce a crack-advance mechanism operating uniquely in cyclic fatigue. Possible mechanisms are alternating crack tip blunting and resharpening or, for whiskerreinforced composites, whisker breakage. Extrinsic mechanisms may not involve a change in the crack propagation mechanism under cyclic fatigue condition. Instead, the unloading may change the value of the crack tip shielding. Thus cyclic fatigue might reduce the crack tip shielding effect of transformation toughening or crack tip bridging.

\section{Rolling Contact Fatigue Testing}

Many test-rig types are used to study rolling contact fatigue performance of ceramics. Typically, in such tests, a detector coupled with a shutdown device is used to monitor the vibration of the assembly. When a pre-set vibration level is exceeded, indicating the formation of a spall of 
excessive uneven wear, the test is automatically stopped and lifetime of the test is recorded. Alternatively, the tests are suspended at different durations to study the wear rate. The characteristics of various types of rolling contact fatigue test method used in UK, Japan, and US are summarized below.

\subsection{The Modified Four-Ball Machine/Five-Ball Machine}

A model contact consisting of three lower balls driven by a fourth contacting upper ball simulates conditions within a standard deep-groove ball bearing. The upper ball models the bearing race, while the cup simulates the bearing outer race and the three planetary balls represent the balls within a ball bearing. This simulates the rolling and sliding produced in an angular contact ball bearing. The loading geometry is shown in Fig. 2. The machine has a proven history as being useful to investigate the rolling contact fatigue resistance of materials under various tribological conditions. Previously, this machine has been mainly used as an accelerated method to measure the rolling contact fatigue of bearing steels by various research staff. The influence of lubrication type on steel ball rolling contact fatigue was also evaluated using the machine [32-34]. The Institute of Petroleum gathered various papers [35], which describes various test results, ball dynamics and kinematics using the modified four ball machine. The RCF performance of hot-pressed $\mathrm{Si}_{3} \mathrm{~N}_{4}$ bearing materials has been studied in the past by Scott [36] and Scott and Blackwell [37], using this machine. Recently, Hadfield et al. [38-40] have used the modified four-ball machine to simulate the rolling contact in hybrid ball bearings. 


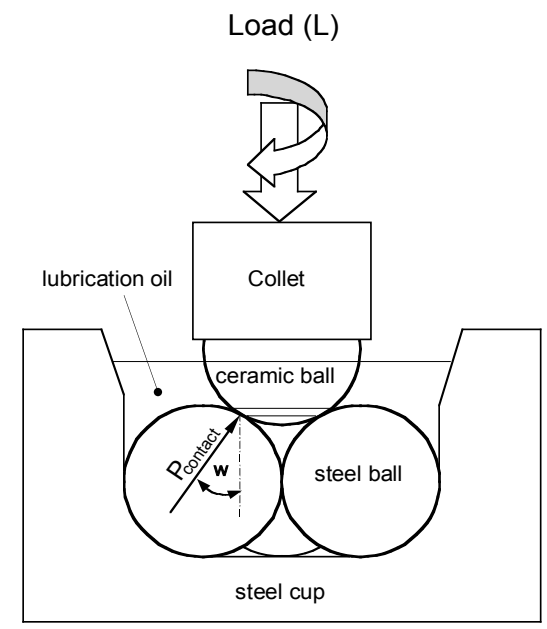

Figure 2. Loading configuration of four-ball machine.

The five-ball test assembly is similar to a four-ball one, which consists of a driven test ball on top of four lower balls positioned by a separator, in the form of a pyramid. The contact geometry and the rotating mechanisms of the test rig are shown in Fig. 3. The four lower balls rotate in a race driven by the upper ball, thus simulating the rolling and sliding produced in angular contact ball bearing. This five-ball machine has been used to investigate the fatigue life of high-speed ball bearings with hot pressed $\mathrm{Si}_{3} \mathrm{~N}_{4}$ balls [41-42].

There are many advantages to the ball-on-ball testers - they perhaps are the most attractive RCF test methods of those described here because of their ability to capture the many nuances of ball bearing fatigue. The loading setup and action simulates conditions within a standard deepgroove ball bearing. The upper ball models the inner race while, the cup simulates the bearing outer race, and the three planetary balls represent the balls in a ball bearing. 


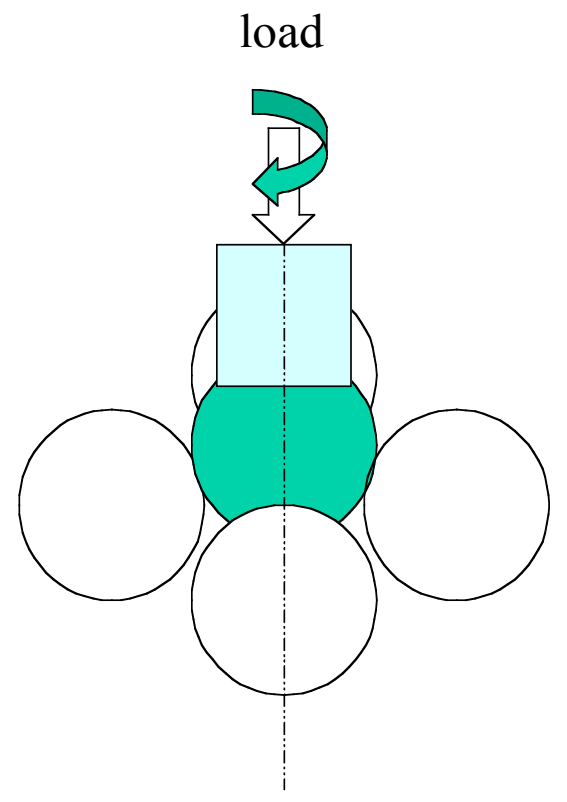

Figure 3. Loading configuration of five-ball machine.

\subsection{Ball-on-Plate (Ball-on-Flat) Machine}

A cross section view of the test rig in shown in Fig. 4. The test unit has a unidirectional thrust bearing configuration, which consists of three balls or rollers equally spaced at $120^{\circ}$ by a retainer and loaded between a stationary flat washer (bottom in Fig. 4) and a rotating grooved washer (top in Fig. 4). The rotating washer produces ball motion and serves to transmit load to the balls (or rollers) and the flat washer. The ball-on-plate machine was used to investigate the rolling contact fatigue performance of $\mathrm{Si}_{3} \mathrm{~N}_{4}$ balls [43-44].

The advantage of the ball-on-plate test method is it enables the study of RCF response when a ceramic ball is in rolling contact with a flat surface - a condition that in fact exists in many hybrid bearing applications. 


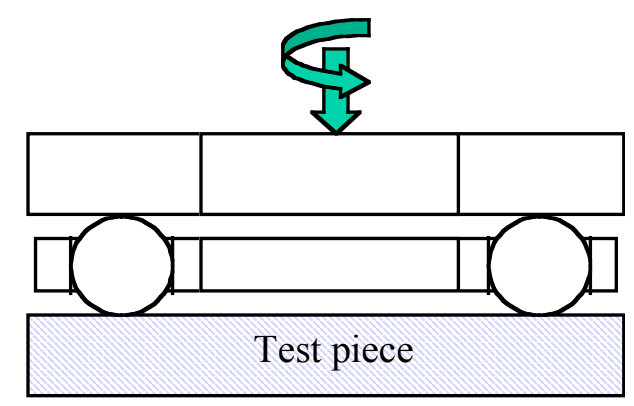

Figure 4. Loading configuration of ball-on-plate machine.

\subsection{Ball-on-Rod Machine}

The loading geometry of the ball on rod type testing machine is shown in Fig. 5. This RCF bench tester was first developed by the Ball and Roller Bearing Group of Federal-Mogul, and the design detail was described by Glover [45]. Three steel balls, $12.7 \mathrm{~mm}$ in diameter, orbit a rotating $9.53 \mathrm{~mm}$ diameter cylinder test specimen. Precision collet was used to hold the testing rod in a strict vertical position. Cowley defined a standardized method to finish the testing rods which was used on this tester. The depth-of-cut at rough, intermediate and finish grinding stages was detailed by Chao [46]. The thrust load on the bearing cups is applied mechanically by forcing the upper cup towards the lower cup with three precalibrated coil springs in the assembly. The rod specimen is rotated by a direct-drive electric motor mounted in line with the specimen below the table. The three balls are, in turn, driven by the rod and rotate around the rod. Lubricant is supplied by drip feeding onto the top of the rod. This machine had been employed to study rolling-contact wear performance of the steel ball and $\mathrm{Si}_{3} \mathrm{~N}_{4}$ rod contact and all ceramics contact [47-48]. Wear performance of several $\mathrm{Si}_{3} \mathrm{~N}_{4}$ materials was investigated using this machine [49]. The effects of microstructure, composition and physical properties on rolling-contact wear and fatigue performance were also studied respectively on this machine by researchers [50-51]. 
The advantage of the three-ball-on-rod tester is it facilitates inexpensive initial testing of new silicon nitride compositions because machining ceramic rods is much cheaper than machining ceramic spheres. Another advantage is that its loading configuration mimicks the ball-on-flat scenario that exists in many hybrid bearings. The disadvantage of it though is the surface finishing of rods and balls produce different types and amounts of subsurface damage, so the testing of a ceramic rod does not necessarily reflect how the same ceramic machined in spherical form will perform under conditions of rolling contact. Also, existing three-ball-on-rod testers were developed with the testing of metallic components in mind, so the applied compressive loads (i.e., contact stresses) are limited and usually are too low to enable the study of RCF capability of the ceramic when metal-ceramic paired combinations form the study.

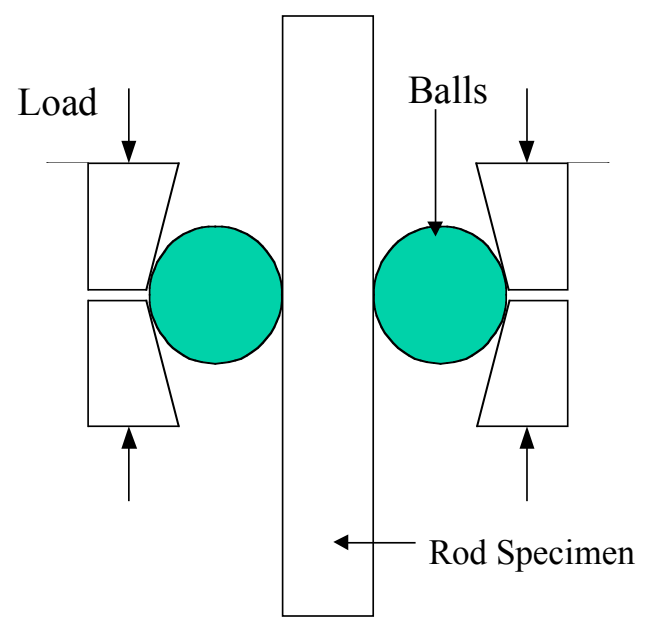

Figure 5. Loading configuration of ball-on-rod machine.

A Japanese type of ball-on-rod tester was used to investigate RCF performance of ceramics by Nishihara [52]. In this method, two balls one-half inch $(12.7 \mathrm{~mm})$ in diameter, are supported by three rollers which are pressed against a spinning bearing steel rod as shown in Fig. 6. 
The advantage of the ball-on-rod testers is they facilitate inexpensive initial testing of new silicon nitride compositions because machining ceramic rods is much more economical than machining ceramic spheres. Another advantage is that its loading configuration mimicks the ball-on-flat scenario that exists in many hybrid bearings. The disadvantage of them though is the surface finishing of rods and balls produce different types and amounts of subsurface damage, so the testing of a ceramic rod does not necessarily reflect how the same ceramic machined in spherical form will perform under conditions of rolling contact. Also, in the case of the threeball-on-rod tester, it was developed with the testing of metallic components in mind, so the applied compressive loads (i.e., contact stresses) are limited and usually are too low to enable the study of RCF capability of the ceramic when metal-ceramic paired combinations form the study. If one wants to learn what the RCF capability of silicon nitride balls are, then it is almost impossible to identify what that potential is unless uses the three-ball-on-rod tester to test those ceramic balls against a ceramic rod. This latter option can also be problematic because the RCF of a ceramic ball against another ceramic will be different than when it is in contact with a metal.

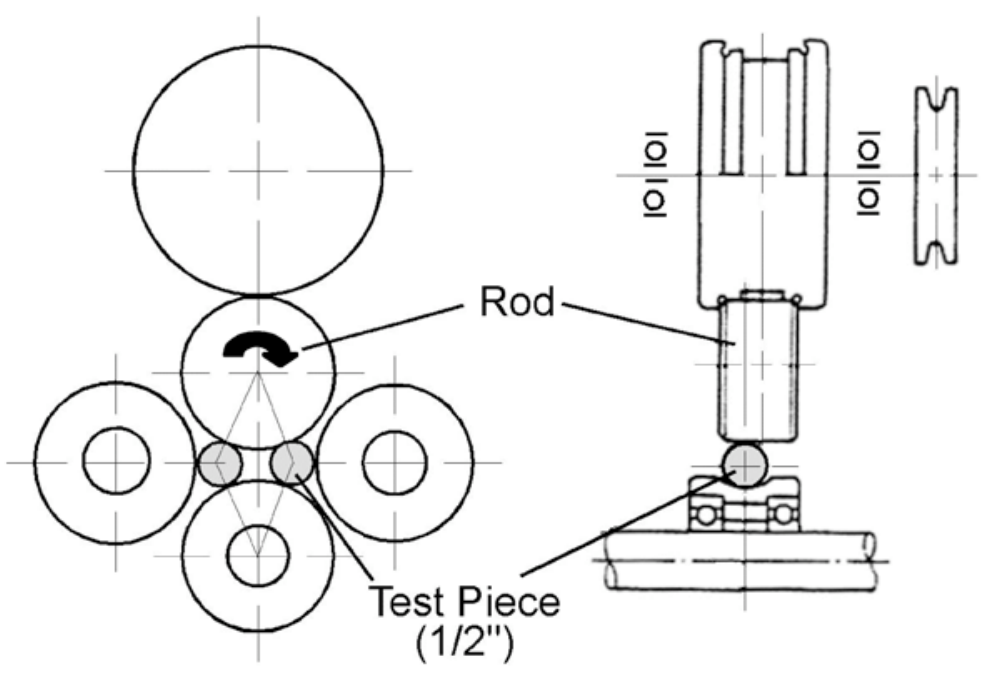

Figure 6. Japanese type ball-on-rod machine [52]. 


\subsection{Disc-on-Rod Machine}

A disc-on-rod machine is shown in Fig. 7. Two steel discs, $177.7 \mathrm{~mm}$ in diameter and $12.7 \mathrm{~mm}$ thick, are pressed against the test specimen, which is held in a spindle and driven at $10000 \mathrm{rpm}$. The test specimen is a $76 \mathrm{~mm}$ long, straight cylinder with a $9.52 \mathrm{~mm}$ diameter. With the known geometry, the contact stresses as a function of load can be calculated. The machine provides a means of rapid testing. The specimen receives $1,200,000$ stress cycles per hour when driven at $10,000 \mathrm{rpm}$. Earlier work using this machine was performed by some researchers [53-54].

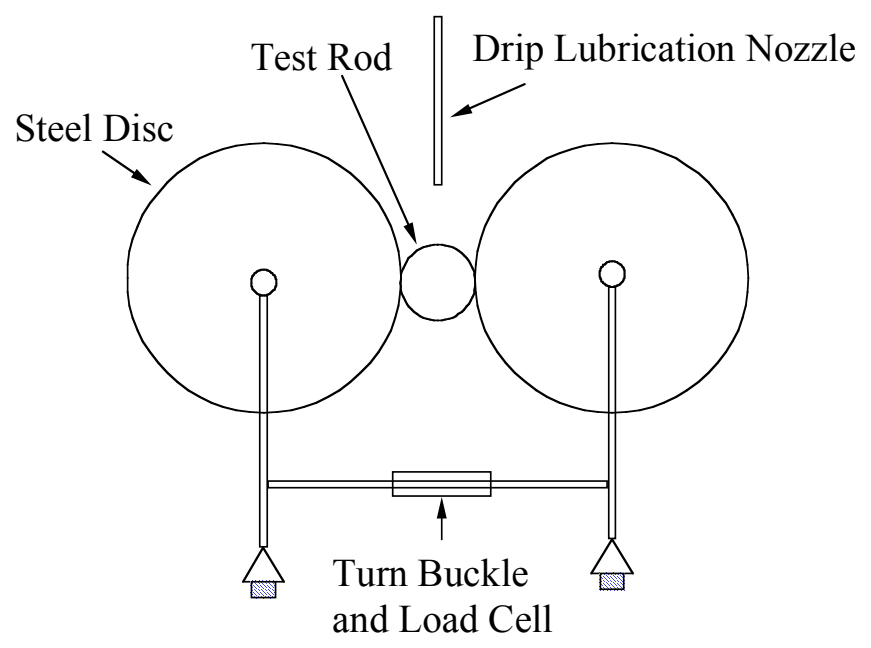

Figure 7. Loading configuration of disc-on-rod machine. 


\subsection{Contacting Ring (Cylinder-on-Cylinder) Machine}

A diagram of the test rig developed by Otsuka [55] is shown in Fig. 8. The rig uses two diskshaped specimens rotating against each other on their outer surfaces. The contacting outer surface of the specimens can be both flat or, one specimen may have a flat surface while the other has a toroidal surface. The rotational speeds of the two rings (cylinders) can be controlled individually with separate motors or using the gear mechanism; thus, rolling contact with differing amount of sliding (slippage) at the interface can be generated. The driver ring is normally made of martensitic stainless steel. Typically, the load is applied using a compressed coil spring or dead weight loading systems. Tests can be conducted in either dry or lubricated conditions. Profiles of the wear scars on the contact surfaces can be used to estimate the wear volume. The contact ring machine has been used to investigate wear performance of ceramics [56-58].

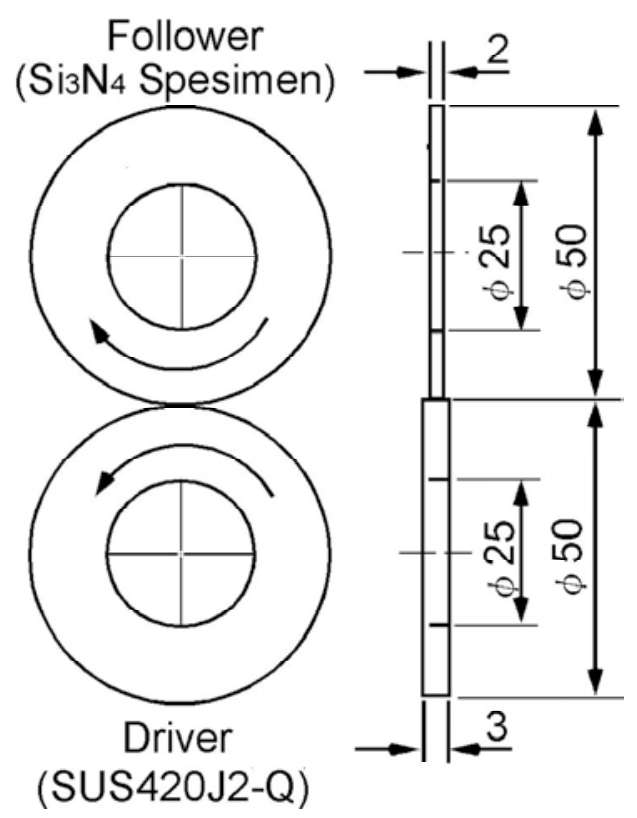

Figure 8. Contacting ring (cylinder on cylinder) machine. 


\section{Failure Modes of Rolling Contact Fatigue}

As previous discussed, many test-rig types are used to investigate $\mathrm{RCF}$ of $\mathrm{Si}_{3} \mathrm{~N}_{4}$ bearing materials. The RCF performance and failure modes were influenced by the test-rig type [59] and failure modes could be changed according to contact geometry. The experimental evaluation of $\mathrm{Si}_{3} \mathrm{~N}_{4}$ should therefore be conducted using several different test methods before predicting RCF performance. Several failure modes of $\mathrm{Si}_{3} \mathrm{~N}_{4}$ in rolling contact have been reported, i.e., spalling fatigue failure, delamination failure and rolling contact wear.

\subsection{Spalling Fatigue Failure}

Spalling describes a specific form of surface damage and it is the most common mode of failure in rolling contact fatigue tests. Silicon nitride spalls in a manner similar to bearing steels, which is, in fact, one of the reasons for $\mathrm{Si}_{3} \mathrm{~N}_{4}$ being a good candidate for replacing bearing steels. Other structural ceramics, for example, $\mathrm{SiC}$, typically fail by catastrophic fracture due to their low fracture toughness or severe wear by micro-fracture. Catastrophic failure can cause damage to the entire bearing assembly.

The spalling fatigue mode has been produced in various test machines [42-43, 49, 51, 54-55, 60]. For example, Parker and Zaretsky [42] using a five-ball machine investigated the fatigue life of hot-pressed $\mathrm{Si}_{3} \mathrm{~N}_{4}$ balls. Lubricated contact was studied with $12.7 \mathrm{~mm}$ diameter balls, Hertz stresses ranging from 4.3 to $6.2 \mathrm{GPa}$, a shaft speed of $9600 \mathrm{rpm}$ and a contact angle $30^{\circ}$. There was no evidence of a progressive wear mode of failure, only fatigue spalls similar to those found on steel. Life predictions showed that ceramic-steel contact compared equally to steel-steel contact. Also, Lueck and Cowley [54] investigated the failure mode of hot-pressed ceramic using a disc-on-rod machine. All failures were of a spalling, non-catastrophic nature, and test loads varied from 4.1-5.5 GPa. The results inferred that $\mathrm{Si}_{3} \mathrm{~N}_{4}$ tested under various tribological conditions (e.g., erosion, abrasion, impact wear, etc.) fails in a non-catastrophic mode. Additionally, $\mathrm{Si}_{3} \mathrm{~N}_{4}$ hybrid bearings were tested by Morrison et al. [60], using $12.7 \mathrm{~mm}$ diameter balls, M50 steel rings and a brass cage. Contact pressure ranged between 1.95 and $2.44 \mathrm{GPa}$, and the film parameter was approximately 3.5 for all tests. Spalling was identified as the only mode 
of failure and there were no cases of the $\mathrm{Si}_{3} \mathrm{~N}_{4}$ balls fracturing. Statistical analysis showed that bearing life varies in accordance with a power law model.

Another experimental study [43] examined the dynamic and static load rating of $\mathrm{Si}_{3} \mathrm{~N}_{4}$ as a bearing material. The ball-on-plate machine was employed. Steel balls revolving around an inner race were loaded against a flat test piece. The maximum contact stress was $6.4 \mathrm{GPa}$, the rotational test speed was $1400 \mathrm{rpm}$, and the lubricant was a turbine mineral oil. Spalling was identified as the most common long-term mode of failure. Otsuka [55] investigated the spalling mechanism using a contacting ring tester. Fracture surfaces appeared as a stack of thin layers parallel to the shear stress. Based on these observations, a qualitative model of crack propagation during rolling contact fatigue was developed. As shown in Fig. 9, shear cracks in ceramics are formed beneath the surface; these cracks then coalesce by the formation of lateral cracks propagating transversely to the shear crack planes. Such crack propagation eventually leads to spalling failure.

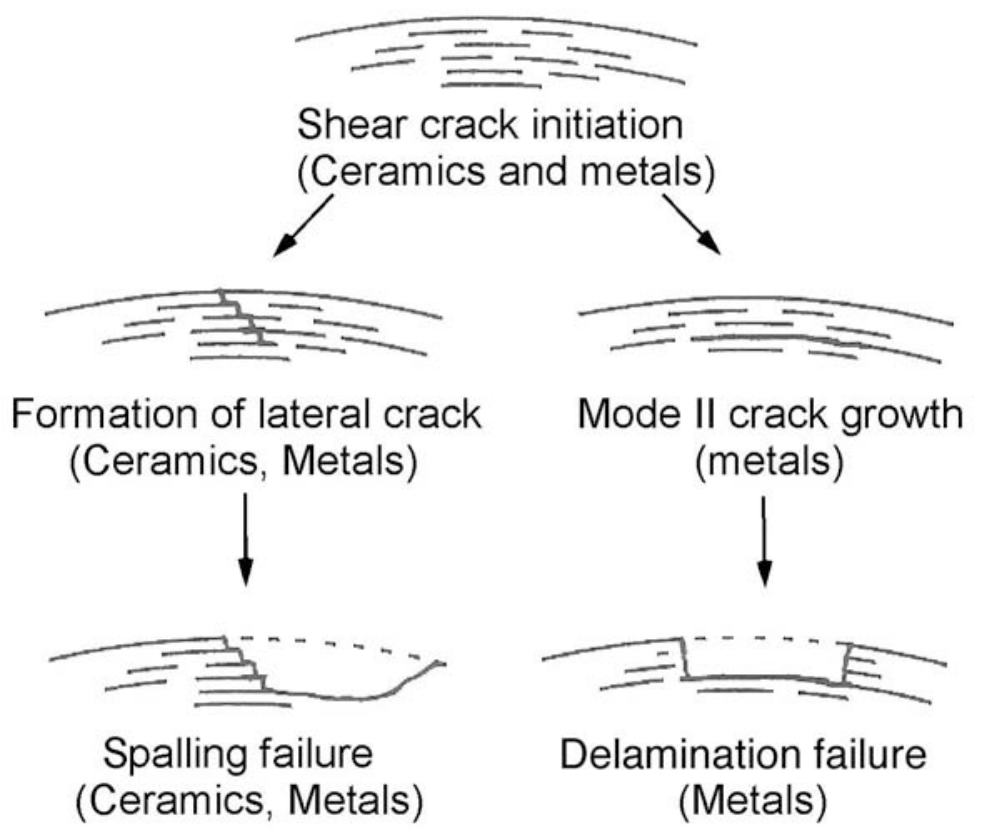

Figure 9. Schematic illustration of the process of rolling contact failure in ceramics and metals. 
Microstructural variations (e.g., grain size and distribution, grain boundary phase and content, porosity, etc.) can be a significant factor in the fatigue failure of rolling contact. Burrier [51] studied the RCF performance using eleven $\mathrm{Si}_{3} \mathrm{~N}_{4}$ bearing materials. These eleven rod blanks were finished by independent source (achieved consistency) to eliminate the effect of surface finishing on the fatigue performance. Tests were conducted using a ball-on-rod machine at maximum contact stress of $5.93 \mathrm{GPa}$ and the rod rotation speed of $3600 \mathrm{rpm}$. Research showed that the materials exhibited differences in life-span of several orders of magnitude and failure mode was spalling fatigue. Silicon nitride materials can exhibit a wide range of rolling contact fatigue endurance. Under the relatively high stress conditions, fatigue durability increased dramatically as the microstructure tended toward finer, more equiaxed grains and a uniform, minimum distribution of second phases. It was also concluded that there was no direct relationship between the fatigue life and bulk physical properties of $\mathrm{Si}_{3} \mathrm{~N}_{4}$, such as density and elastic constant.

Surface defects found on ceramic rolling elements can lead to early or catastrophic failure. Many efforts have been made to investigate their influence on the rolling contact fatigue performance in the past decade [38-39, 61]. Hadfield [61] has extensively studied the failure modes of ring, radial and lateral pre-cracked ceramic elements under rolling contacts. The stages of the ring-crack failure process in the form of fatigue spalling on the ceramic surface and subsurface were also investigated [39]. The results revealed that the pre-cracked ceramic ball failed in a non-catastrophic spalling mode. The typical images of surface failures from artificially induced ring/cone cracks are shown in Fig. 10. 


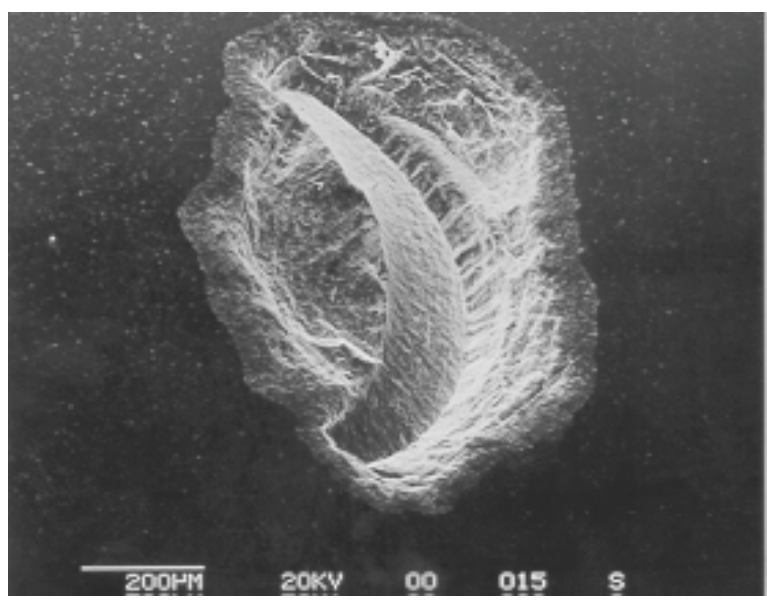

(a)

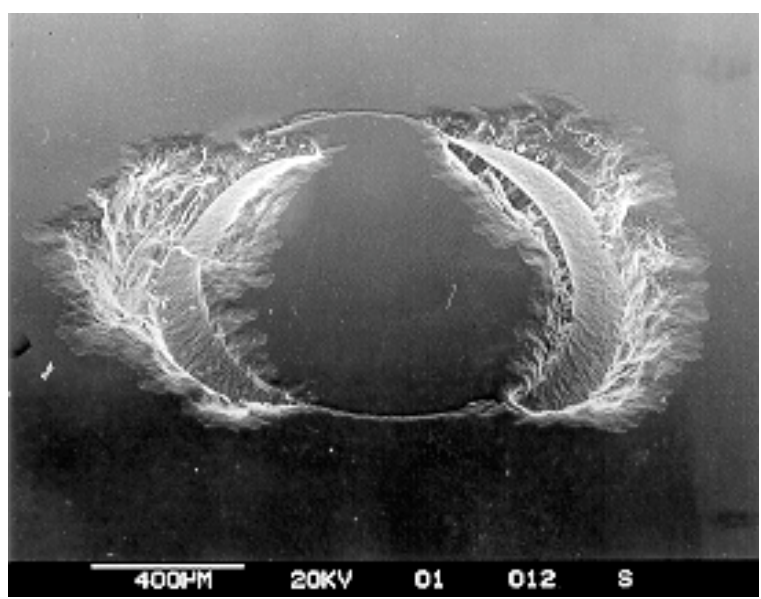

(b)

Figure 10. Spalling fatigue failure resulting from artificially induced ring /cone cracks (SEM micrographs). (a) Single spall and (b) double spall.

All those results placed high reliance on random crack location and did not focus on the significance of specific crack locations. In another study [62], a new rolling contact fatigue test method was devised for positioning the ring crack and hence the surface ring crack was located precisely within the contact path. The results showed that the 'natural' ring crack failure is dependent on the crack location within the contact path. Fatigue failure happens only in a few crack locations/orientations. The loading condition geometry of the test machine and the geometric orientations are shown in Fig. 11. Surface observations from different crack orientations are shown in Fig. 12. A fracture mechanics approach has been utilized to explain the influence of crack location on rolling contact fatigue performance. The reason for differences in rolling contact fatigue performance is that different crack locations have different stress intensity factor values and orientation of maximum tensile stress which team to govern the crack propagation behavior [63]. It should be noted that fatigue spalling processes may be involved in the original ring crack propagation as well as that of the secondary surface cracks induced as the crack grows [64]. Hence, the fatigue life cannot be simply determined in terms of the propagation life of the surface crack and the subsequent surface damage also plays an important role in the whole life prediction. A typical cross-sectional image of the spalling fatigue failure found on the ceramic balls is illustrated in Fig. 13 [64]. 


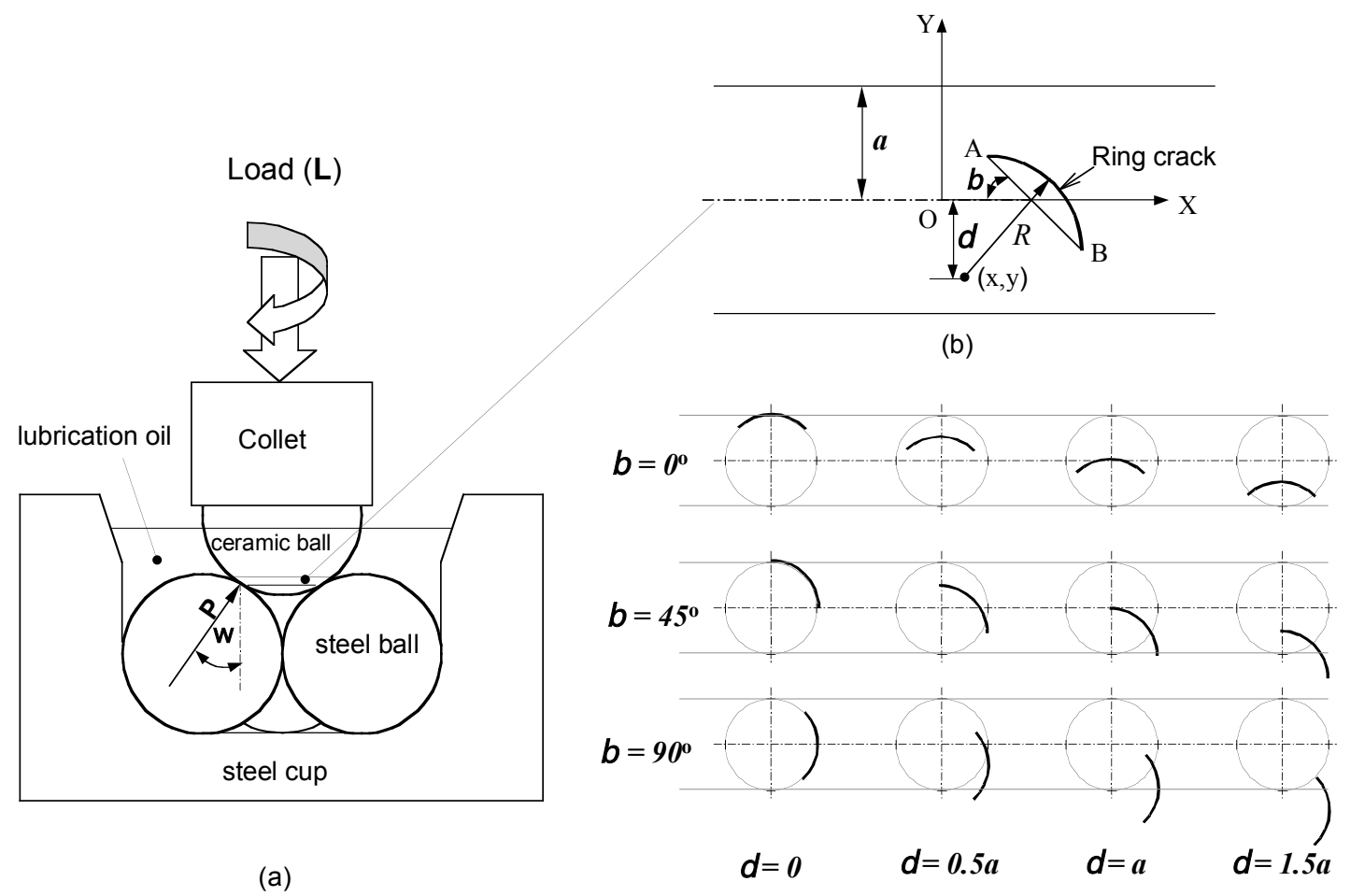

(c)

Figure 11. Loading configuration and ring crack location on the contact track. (a) Loading system. (b) Geometric location on the contact track. (c) Twelve typical locations within the contact path. 


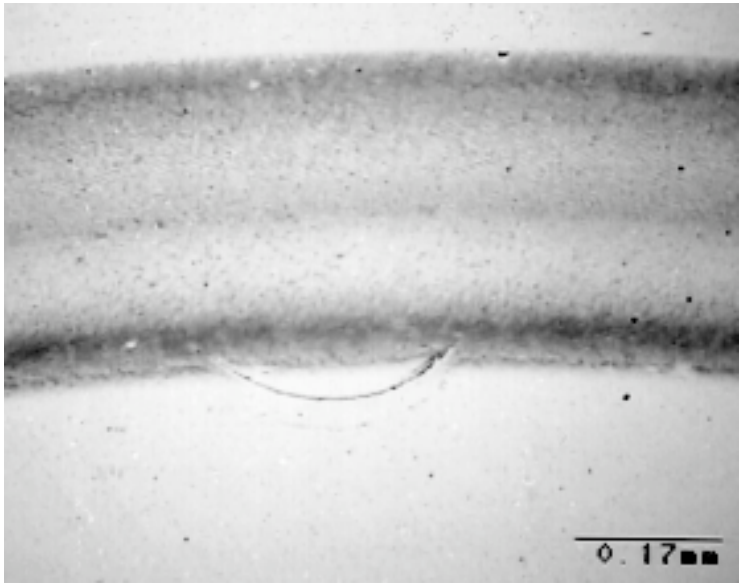

(a)

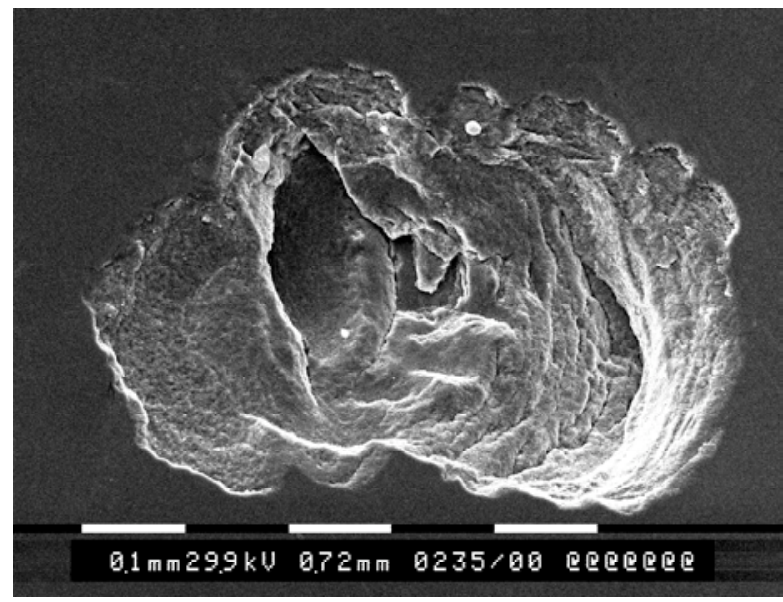

(c)

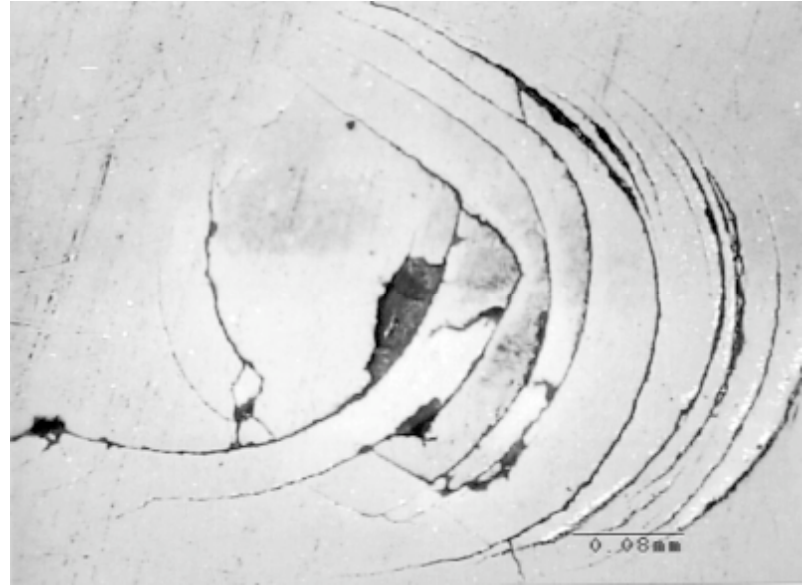

(b)

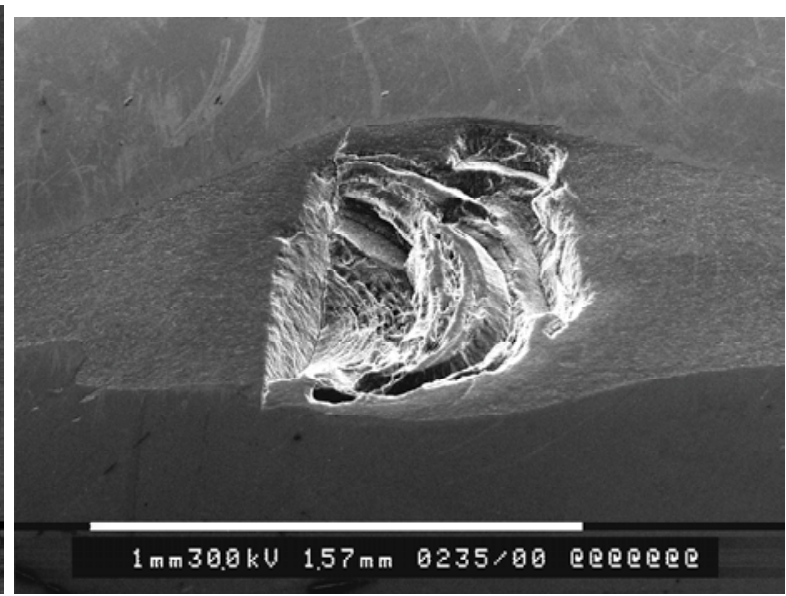

(d)

Figure 12. Surface fatigue damage resulting from 'natural' ring cracks (Figs. 10(a)-(c)) and line defects (Fig. 10(d)). (a) Ring cracks and wear track after 113 million stress cycles at crack location $\beta=0^{\circ}$ and $\delta=0$ (optical micrograph). (b) Incipient failure after 27 million stress cycles at the crack location $\beta=45^{\circ}$ and $\delta=0$ (optical micrograph). (c) Spall SEM micrograph after 16 million stress cycles at crack location $\beta=90^{\circ}$ and $\delta=0$. (d) Spall SEM micrograph after 1.4 million stress cycles at $\beta=90^{\circ}$. White markers in (c) and (d) represent 100 and $1000 \mu \mathrm{m}$, respectively. 

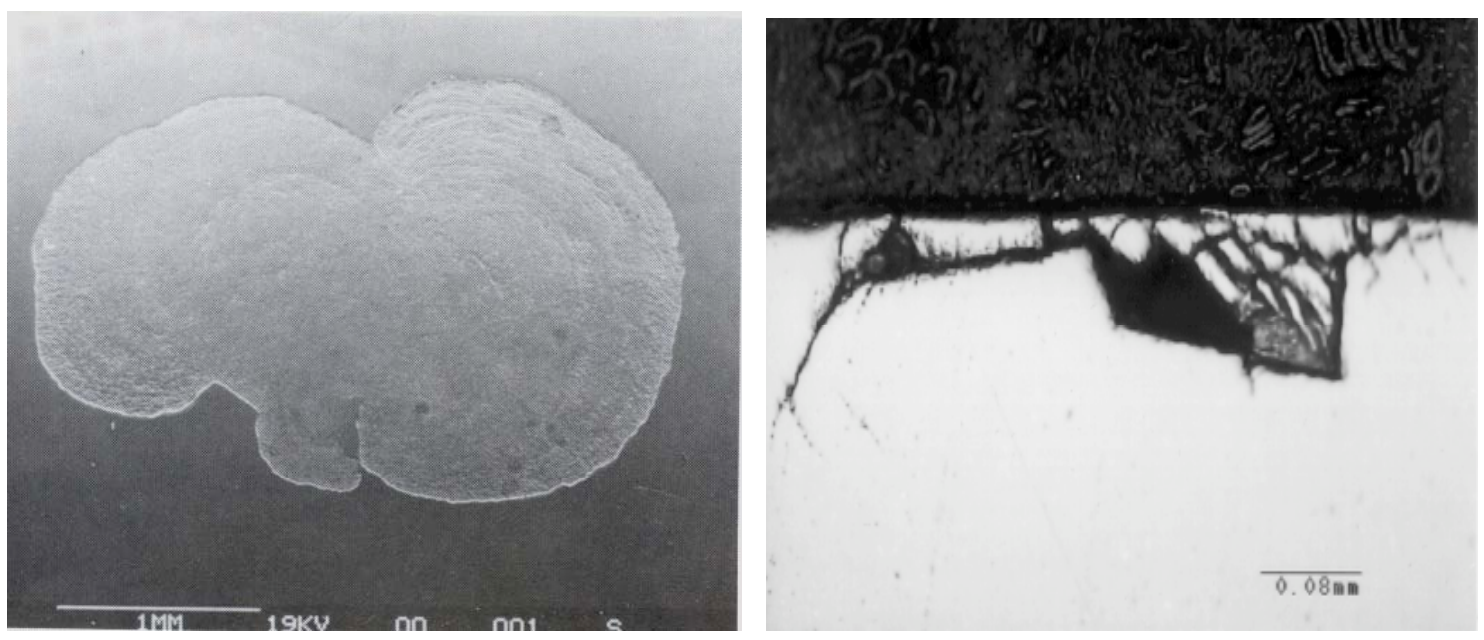

Figure 13. Surface (left) and subsurface (right) observations of spalling fatigue failure.

\subsection{Delamination Failure}

Studies of delamination fatigue failure on as-finished and artificially pre-cracked $\mathrm{Si}_{3} \mathrm{~N}_{4}$ balls were carried out using a modified four-ball machine [38, 61, 65-66]. The $\mathrm{Si}_{3} \mathrm{~N}_{4}$ balls were in rolling contact with a steel ball to simulate the rolling condition of a hybrid bearing. The cracks were artificially induced, being in the forms of ring cracks or radial and lateral cracks. Testing under highly compressive cyclic stress and various tribological conditions resulted in delamination failure. Scanning electron microscope observations enabled the delamination failures to be classified by the location of crack initiation and subsequent propagation. For radial and lateral cracked balls, failure occurred in three ways: [67] lateral crack induced spalling, [67] radial crack induced surface bulging, and [67] radial crack induced delamination. The failure mode was also sensitive to the lubricant used because lubricant could penetrate into the subsurface cracks to produce significant hydrostatic pressure. Typical images of such damage are shown in Fig. 14. 


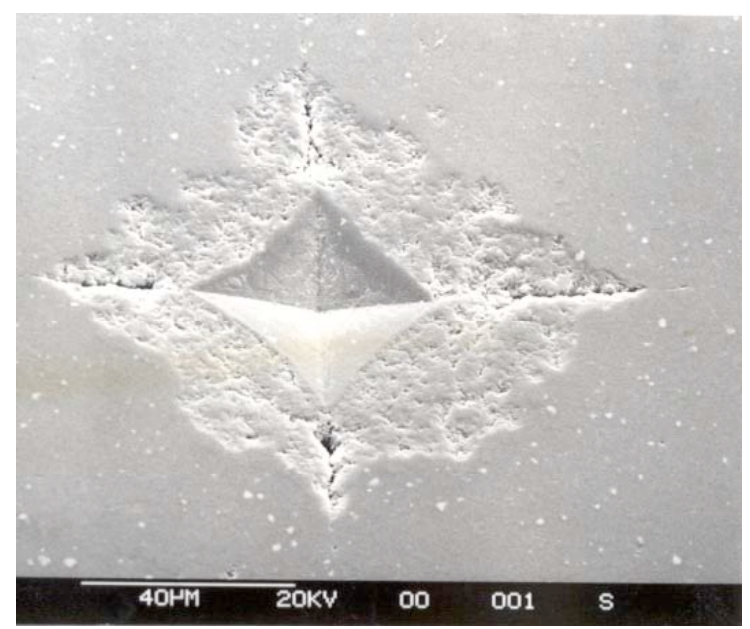

(a)

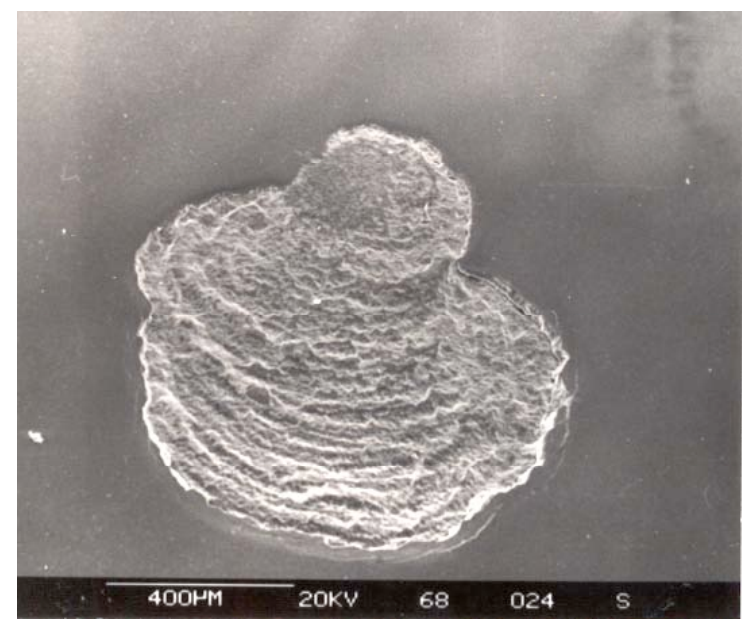

(c)

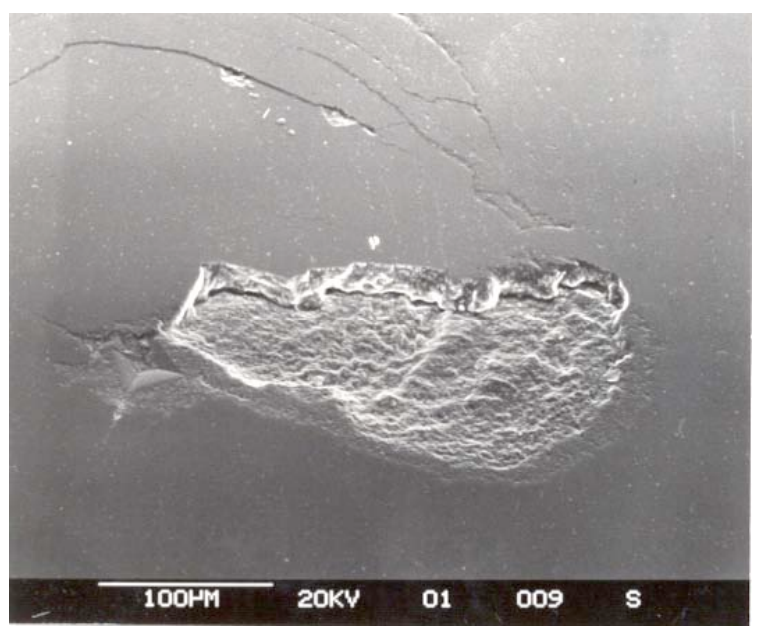

(b)

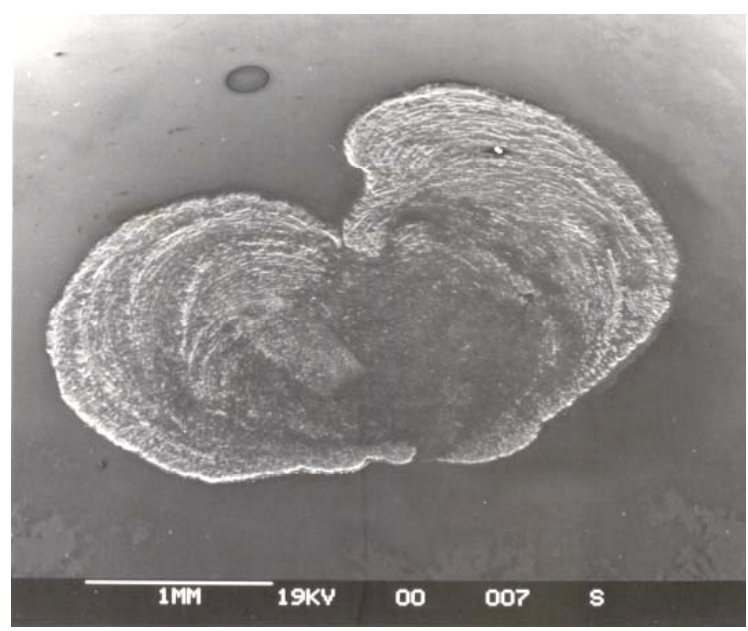

(d)

Figure 14. Surface damage resulting from ceramic/steel contact (SEM micrographs). (a) Lateral crack spall. (b) Radial crack propagation and Ceramic/ceramic contact at high Hertz contact pressure.

(c) delamination and (d)

In the case of surface delamination, adjacent radial cracks were propagated and connected, the delamination area showed typical fatigue striations. Residual stress measurement by x-ray diffraction indicated compressive stress in the delaminated area. In the case of surface bulging, ferrous debris originating from the upper steel ball was trapped under the ceramic ball's surface. The steel debris, suspended in the pressurized lubricant, was forced up through the ball surface. 


\subsection{Rolling Contact Wear}

Rolling contact wear is the most common type found on the contact path and it has been reported by a number of researchers. Preliminary work using a modified four-ball machine to assess hotpressed $\mathrm{Si}_{3} \mathrm{~N}_{4}$ as a rolling material was reported by Scott and Blackwell [37]. Unlubricated contact was studied at different temperatures at $1500 \mathrm{rpm}$ and a maximum Hertzian stress of 5.8 GPa. Lubricated contact was also studied at 7.7 GPa and ambient temperature. Under unlubricated conditions, upper ball wear after 30 minutes was measured as $0.6 \mathrm{mg}$, and the wear track on the ball surface retained modest surface quality. For lubricated contact, failure occurred to the upper ball after 20 seconds, the failure mode being wear and fracture. $\mathrm{A} \mathrm{Si}_{3} \mathrm{~N}_{4}$ upper ball was tested in contact with an En31 bearing steel (similar to AISI $52100 \mathrm{Cr}$-steel) lower ball and this increased the time of failure to 70 seconds.

Wear properties of $\mathrm{Si}_{3} \mathrm{~N}_{4}$ in dry rolling-sliding contact were studied using a contacting ring test machine. Under no lubrication and a maximum Hertzian pressure of $1.1 \mathrm{GPa}$, results showed thin flake-like wear particles that were rich in oxygen and depended on the roughness of the contact surfaces. Braza [56] carried out rolling and sliding wear mechanism experiments. This work involved the use of a large diameter cast iron roller contacting with a smaller diameter $\mathrm{Si}_{3} \mathrm{~N}_{4}$ roller with an internal steel pin lubricated with an oil. Contact pressure was small, i.e., 1.37 $\mathrm{GPa}$, and three types of $\mathrm{Si}_{3} \mathrm{~N}_{4}$ were tested: hot pressed, pressureless sintered and reaction bonded. The wear rate for the reaction-bonded type was higher, the wear mode being by 'grain pullout'. The other two types had similar wear rates, the modes of wear being submicron chipping. Rolling contact friction coefficients were all about 0.0056. Dry rolling tests [68] on several ceramics concluded that the $\mathrm{Si}_{3} \mathrm{~N}_{4}$ wear rate was the smallest. A ring-on-disc testing machine was used, with the maximum Hertz stress ranging from $2.5 \mathrm{GPa}$ to $5 \mathrm{GPa}$. A relation between wear rate and mechanical properties was attempted without success, suggesting that a combination of material properties and roughness was needed. Brittle fracture was concluded to be the dominant wear mode. 
A standard ball-on-rod tester was used to study lubricated rolling-contact wear performance of three $\mathrm{Si}_{3} \mathrm{~N}_{4}$ materials, the sintered, hot-pressed and HIPed $\mathrm{Si}_{3} \mathrm{~N}_{4}$. The peak contact pressure was $6.4 \mathrm{GPa}$. Wear rates of these materials ranged over three orders of magnitude, and $\mathrm{HIPed} \mathrm{Si}_{3} \mathrm{~N}_{4}$ exhibited the lowest wear rate [49]. Additional tests were carried out using a ball-on-rod tester. The steel ball and $\mathrm{Si}_{3} \mathrm{~N}_{4}$ rod, lubricated contact was investigated by Lakshminarayanan [48], and it was found that while the steel ball showed a linearly increasing wear rate with the initial contact stress in the range of 3-6.5 GPa, the $\mathrm{Si}_{3} \mathrm{~N}_{4}$ rods exhibited no wear, and only lapped $\mathrm{Si}_{3} \mathrm{~N}_{4}$ showed an occasional spalling failure. Chao [46] studied the self-mated contact of $\mathrm{Si}_{3} \mathrm{~N}_{4}$ under boundary lubrication condition, and a transient wear response was indicated by the results. The initial roughness of both of the balls and rods had a great influence on the nature of transient. The final volume loss also had a direct correlation with the contact load.

The effect of composition and physical properties of $\mathrm{Si}_{3} \mathrm{~N}_{4}$ on rolling wear and fatigue performance was studied using a ball-on-rod machine [50]. Three commercial bearing materials were tested at maximum contact pressure of $6.4 \mathrm{GPa}$. Wear and fatigue properties were compared to physical properties and material composition. It was found that high fracture toughness was not required for high fatigue life and wear resistance. Grain boundary composition did not appear to affect the wear mechanism of these HIPed $\mathrm{Si}_{3} \mathrm{~N}_{4}$. Transient wear of $\mathrm{Si}_{3} \mathrm{~N}_{4}$ in lubricated rolling contact was investigated using a ball-on-rod test machine, with maximum Hertz stress ranging from 5-6.5 GPa. Wear rate and behavior were dependent on the initial surface roughness.

\section{Development in Characterization Techniques of RCF Specimens}

Many techniques have been utilized to characterize the pre- and post- RCF test specimens in order to produce an explanation of rolling contact fatigue properties of $\mathrm{Si}_{3} \mathrm{~N}_{4}$ ceramic materials. Non-destructive testing methods are widely used, including fluorescent dye penetration, resonance ultrasound spectroscopy, scanning acoustic microscopy and many more. A destructive C-sphere strength test was recently developed to examine the subsurface damage in spherical specimens (mainly ball bearing elements) introduced by machining process. 


\subsection{Destructive Evaluation}

\subsubsection{Sphere Compression}

Previous testing has revealed a high correlation between the fatigue life of a bearing and the crushing strength of the rolling elements. A Japanese JIS B1501 standard test was used to demonstrate this by Nishihara [52], and the results are shown in Fig. 15. A distinct trend is evident although there is a high scatter in the data. It implies that a crushing test can serve as a substitute for proof testing of rolling bearing elements if some variability in the results is acceptable.

There are problems with ceramic sphere compression tests though. It is nearly impossible to diametrally compress a ceramic sphere to produce a controlled or predictable fracture. Ring- and cone-crack initiation typically first occur at the two load locations and continue to propagate until ultimate fracture results provide the contact stresses are sufficiently high. The fracture of brittle spheres from diametral compression occurs at such high loads (i.e., a great deal of stored energy exists in the sphere at fracture) that the test coupon disintegrates into fine rubble rendering fractography nearly impossible, and thus, inhibiting the study of the relationship of strength-flaw size. The above chronology is referred to as "crushing", is inherently susceptible to variation, and it can be seen that its interpretation can be subjective. The evolution of ultimate fracture with this test makes the study of strength limitation from inherent flaws or other inhomogeneities located at the surface nearly impossible because fracture analysis is limited by the wide-scale fragmentation and collateral damage among the many particles. 


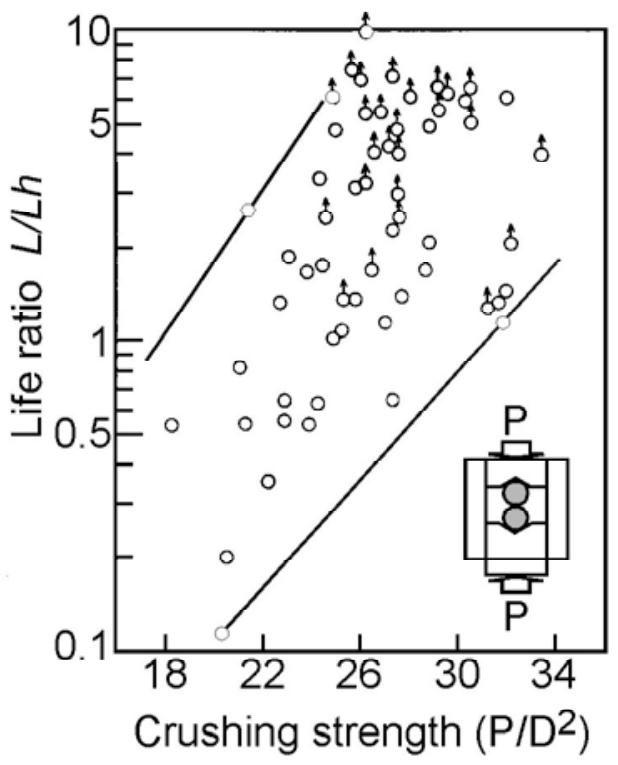

Figure 15. Relationship between crushing strength and life ratio.

\subsubsection{The C-Sphere Flexure Strength Specimen}

In contrast with metals, surprisingly little research, if any, has been devoted to the quantification of sub-surface inhomogeneities (e.g., damage due to machining, residual effects from glass encapsulation used during hot-isostatic-pressing, etc.) in ceramics, and what effect they could have on RCF performance. Such sub-surface inhomogeneities usually play a dominant role in the performance (strength, fatigue, etc.) of structural ceramics. Its study in structural ceramics is typically facilitated using simple tensile or flexure strength specimen geometries that enable the concurrent measurement of strength and strength-limiting flaw size (latter identified through fractographical practices). However, for ceramic spheres, a likely historical barrier of their use to study strength-flaw-size relationships is the inherent geometry of the sphere itself; namely, it is nearly impossible to mechanically load a ceramic ball in a manner to produce a predictable tensile stress field at the sphere's surface sufficient to cause its fracture. Loading a ceramic sphere diametrally produces two Hertzian contacts, and ring- and cone-crack initiation can occur, and ultimate fracture can result if the contact stresses are sufficiently high. However, the evolution of ultimate fracture with this test makes the study of strength limitation from inherent flaws or other inhomogeneities located at the surface nearly impossible. Additionally, the 
fracture of brittle spheres from diametral compression occurs at such high loads (i.e., a great deal of stored energy exists in the sphere at fracture) that the test coupon disintegrates into fine rubble [69] rendering fractography nearly impossible, and thus, inhibiting the study of the relationship of strength-flaw size.

A test coupon called the "C-sphere" flexure strength specimen was recently developed at Oak Ridge National Laboratory to enable the study of, and measurement of, the strength of ceramic spheres and its link to the strength-limiting flaw size. Enabling the identification of a flaw type (usually surface- or near-surface-located) and measurement of its size in finished ceramic balls is indeed important for the study of strength, but more importantly, for the study and predictability of RCF performance (a response limited by surface- or near-surface-located flaws or in changes thereof). Hadfield [40] reported that a critical depth of ring cracking in RCF is 5-20 $\mu \mathrm{m}$ below the surface; the $\mathrm{C}$-sphere specimen is ideal for studying that near-surface depths.

The C-sphere specimen is produced through the controlled slotting of a ceramic sphere (Fig. 16). It is then diametrally loaded (or flexed) to initiate fracture at the sphere's surface or "outer fiber". The C-sphere is analogous to a "C-ring" flexure specimen that is produced through the slotting of a ceramic ring.

In order to work toward an optimized C-sphere geometry, a finite element analysis (FEA) model was created in ANSYS (ANSYS, Canonsburg, PA). The testing of the common ball diameter of $12.7 \mathrm{~mm}$ (0.50 in.) was considered. Candidate slot widths of $3.175 \mathrm{~mm}(0.125 \mathrm{in}$.) and $6.35 \mathrm{~mm}$ (0.25 in.) were considered because they are common sizes for grinding wheel thicknesses, and the $\mathrm{C}$-sphere machining would therefore likely be economical and have associated quick turnaround time. Slot depth was varied until a slot-width-slot-depth combination produced at least a 10-times higher outer-fiber surface tensile (hoop) stress than any other surface tensile stress located elsewhere on the coupon (the geometry of the final C-sphere is shown in Fig. 16). An offset between the original ball's center-line and the center-line of the $3.175 \mathrm{~mm}$ radius was deemed necessary because if the offset is zero or too small, then significant tensile stresses are created on the C-sphere's interior and a high likelihood that fracture would be initiated there because of both the high tensile stress and relatively rough surface finish produced by the 
grinding wheel. The final offset size $(0.635 \mathrm{~mm})$ resulted in a C-sphere geometry that, when diametrally compressed (see Fig. 17), produced an outer-fiber tensile stress much larger than that on the ground interior and therefore a high likelihood that fracture would (desirably) occur there. Stress field in a compressed C-sphere and the relationship between compressive load and maximum Principal Stress are shown in Figs. 18-19, respectively.

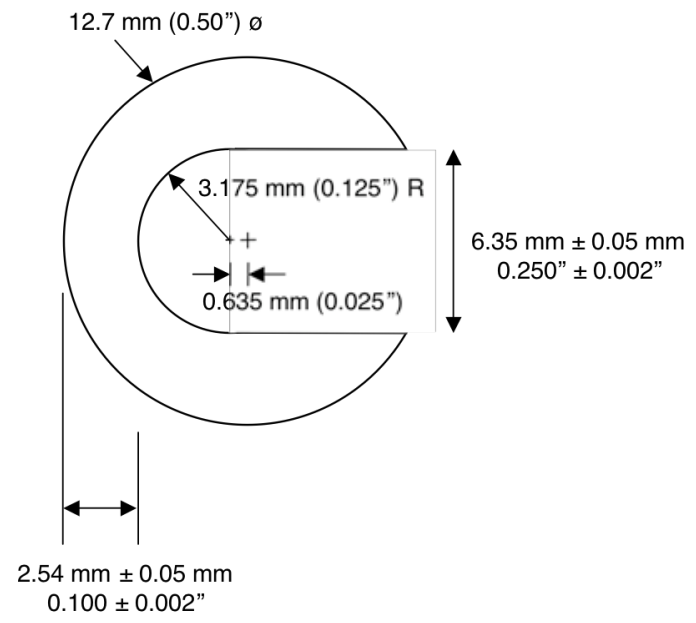

Figure 16. Schematic of the 12.7-mm-diameter C-sphere flexure strength specimen.

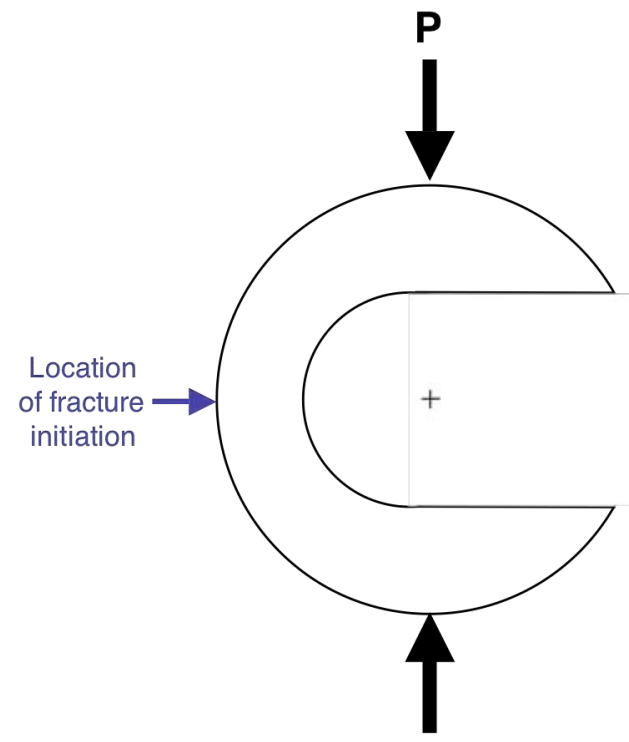

Figure 17. Diametral compression of the C-sphere flexure specimen causes fracture initiation from a hoop stress at the outer fiber. 

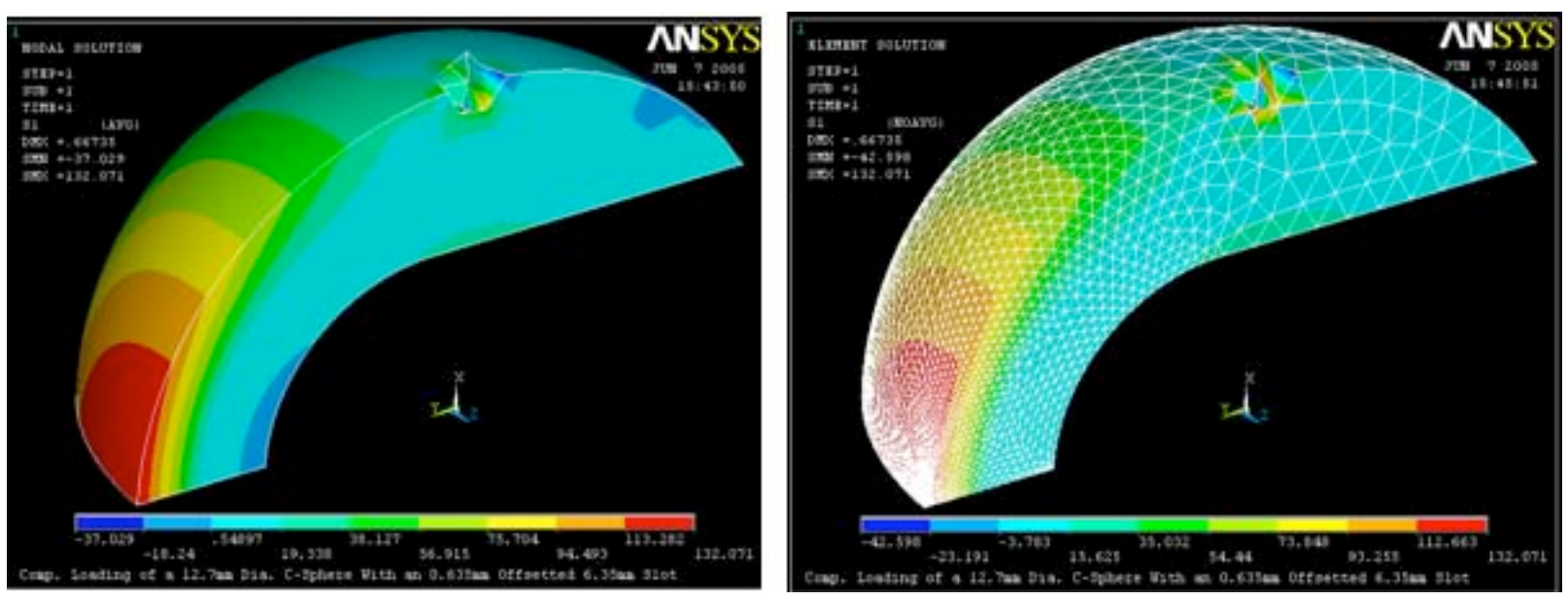

Figure 18. Nodal first principal stress distribution (left) and element $1^{\text {st }}$ Principal stress distribution (right) for the 12.7-mm-diameter C-sphere specimen.

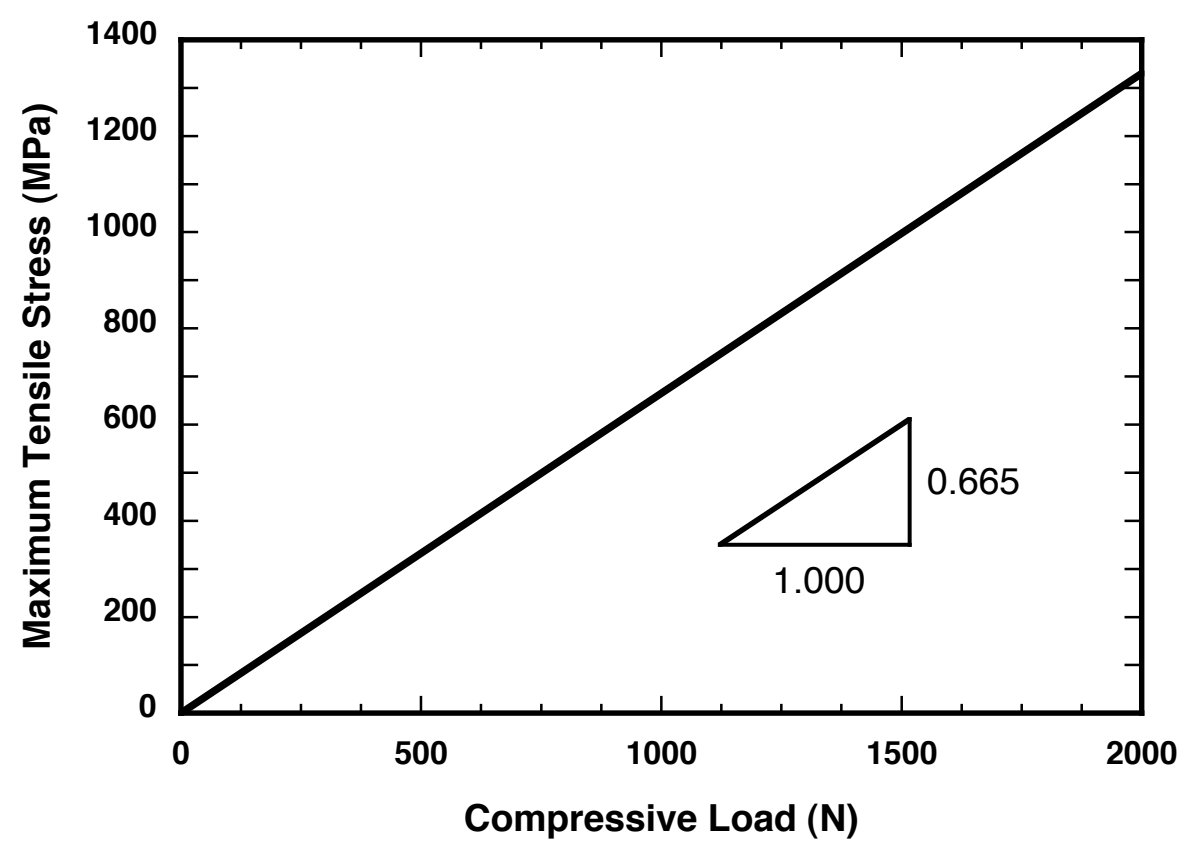

Figure 19. Maximum $1^{\text {st }}$ Principal tensile stress (located at outer fiber - see Fig. 17) as a function of diametral compressive load for the $12.7 \mathrm{~mm}$-diameter C-sphere geometry in Fig. 16 for a $\mathrm{Si}_{3} \mathrm{~N}_{4}$. 
NBD200 and SN101C (Saint-Gobain Ceramics, East Granby, CT) balls with $12.7 \mathrm{~mm}$ diameter were machined into C-sphere flexure strength specimens (Fig. 20). Microstructural images of NBD200 and SN101C are shown in Fig. 21. The static and dynamic hardnesses of both materials were recently quantified [70].

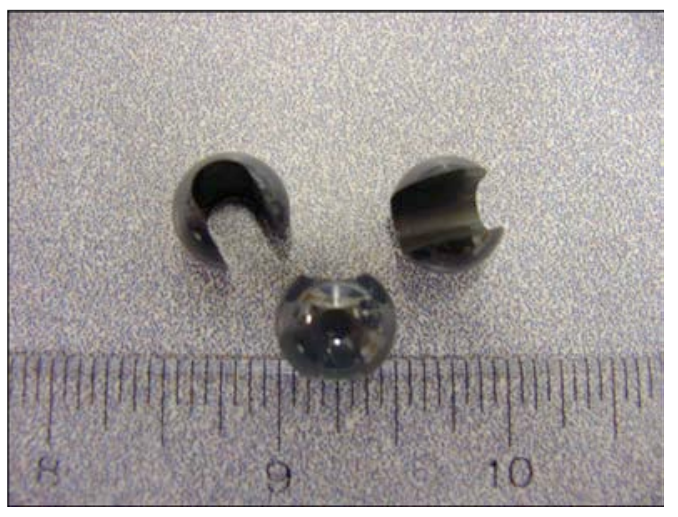

Figure 20. $\mathrm{Si}_{3} \mathrm{~N}_{4} 12.7 \mathrm{~mm}$-diameter $\mathrm{C}$-sphere flexure strength specimens. 


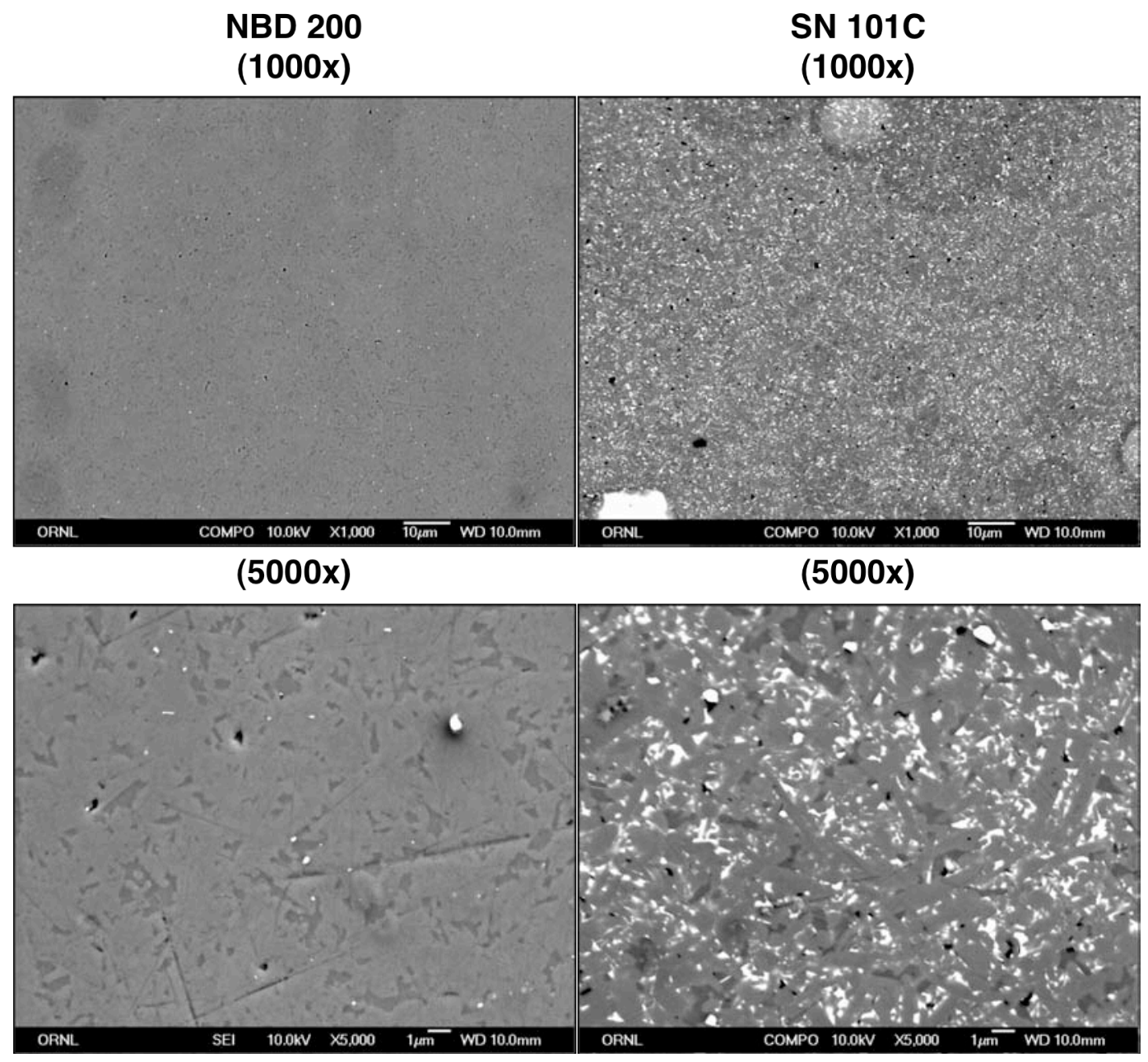

Figure 21. BS-SEM microstructure on finished ball surfaces of NBD200 and SN101C.

C-sphere flexure specimens were monotonically and compressively loaded to failure using an electromechanical universal testing machine at a crosshead displacement rate of $0.5 \mathrm{~mm} / \mathrm{min}$. A special jig was used to horizontally align the C-sphere slot prior to loading. Load to fracture was recorded and used to determine $\mathrm{C}$-sphere flexure strength according to Fig. 19. Weibull strength distributions were determined using maximum likelihood estimation. The C-sphere characteristic strength of the SN101C was approximately 40\% higher than that for the NBD200 (1081 MPa versus $778 \mathrm{MPa}$ ) while their Weibull moduli were statistically equivalent (6.0 and 6.5 , respectively) - both those conclusions are made with $95 \%$ certainty. This difference in strength is illustrated in Figs. 22-23. An example of a failure location is shown in Fig. 24. 


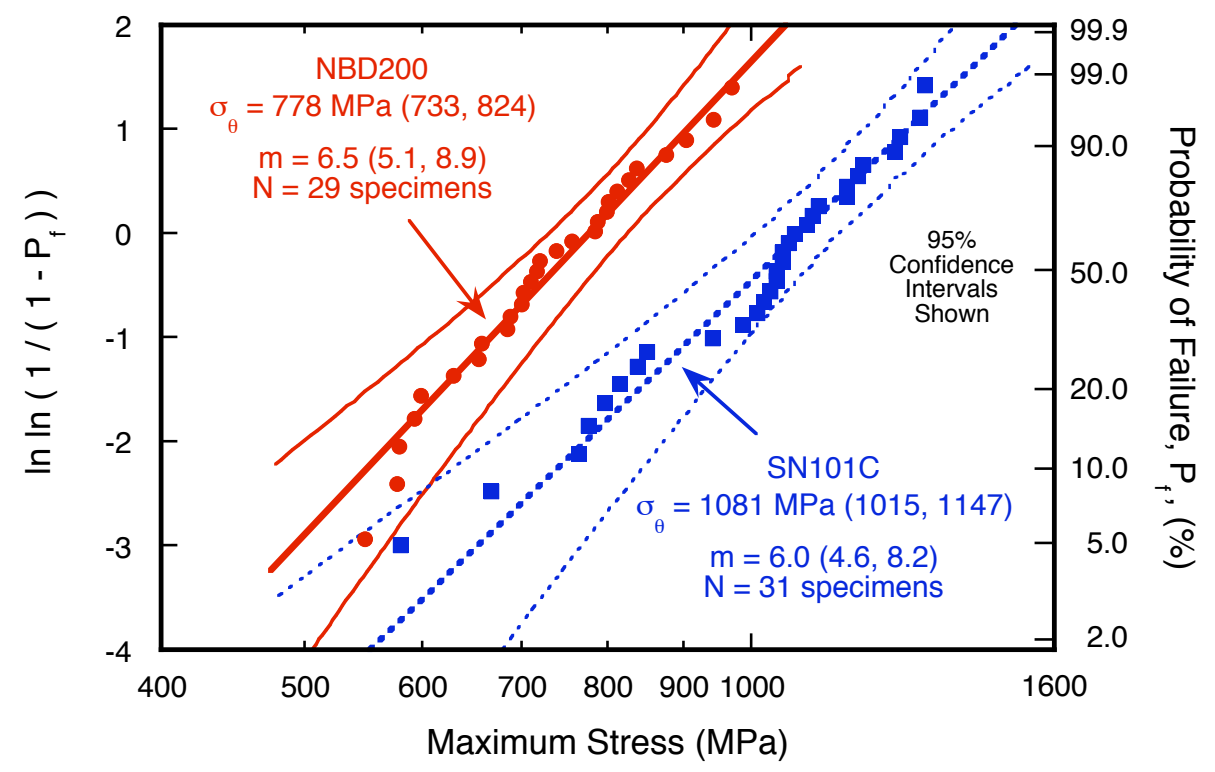

Figure 22. C-sphere Weibull strength distribution comparison of NBD200 and SN101C.

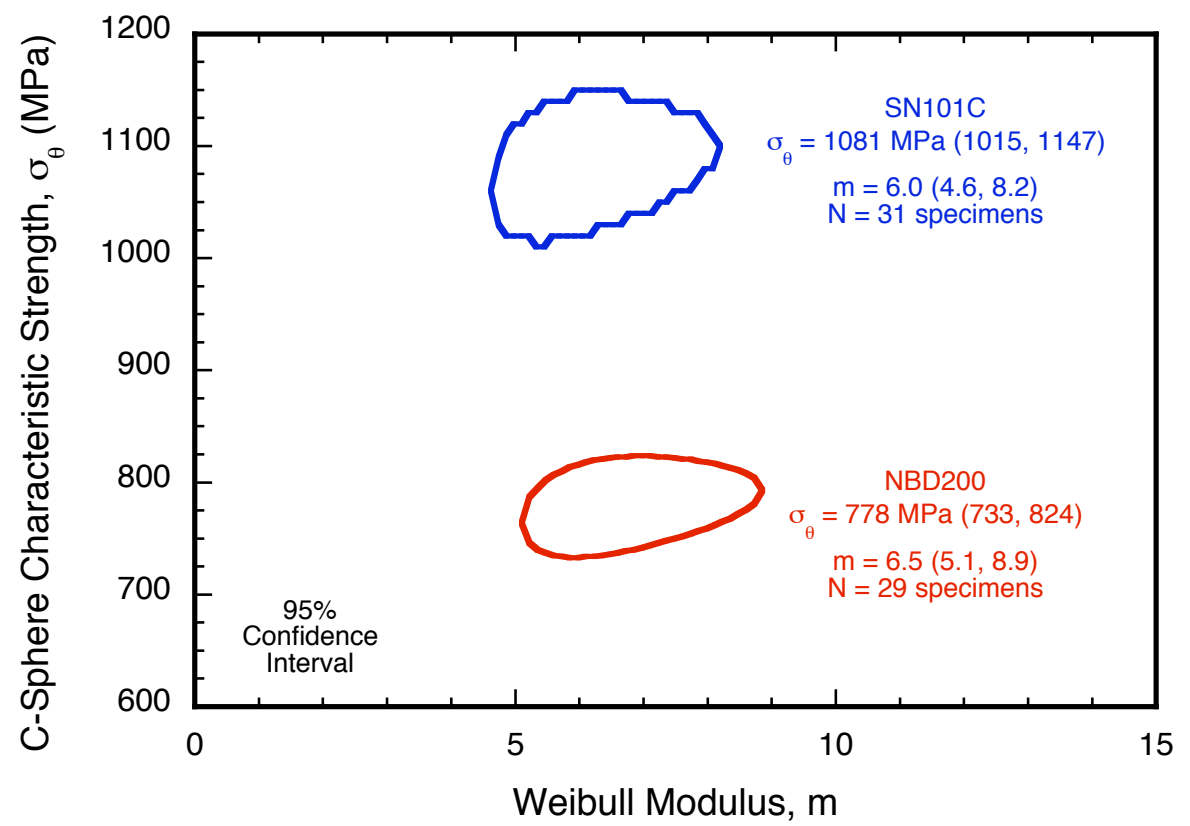

Figure 23. 95\% confidence ratio rings for NBD200 and SN101C C-sphere strengths. 

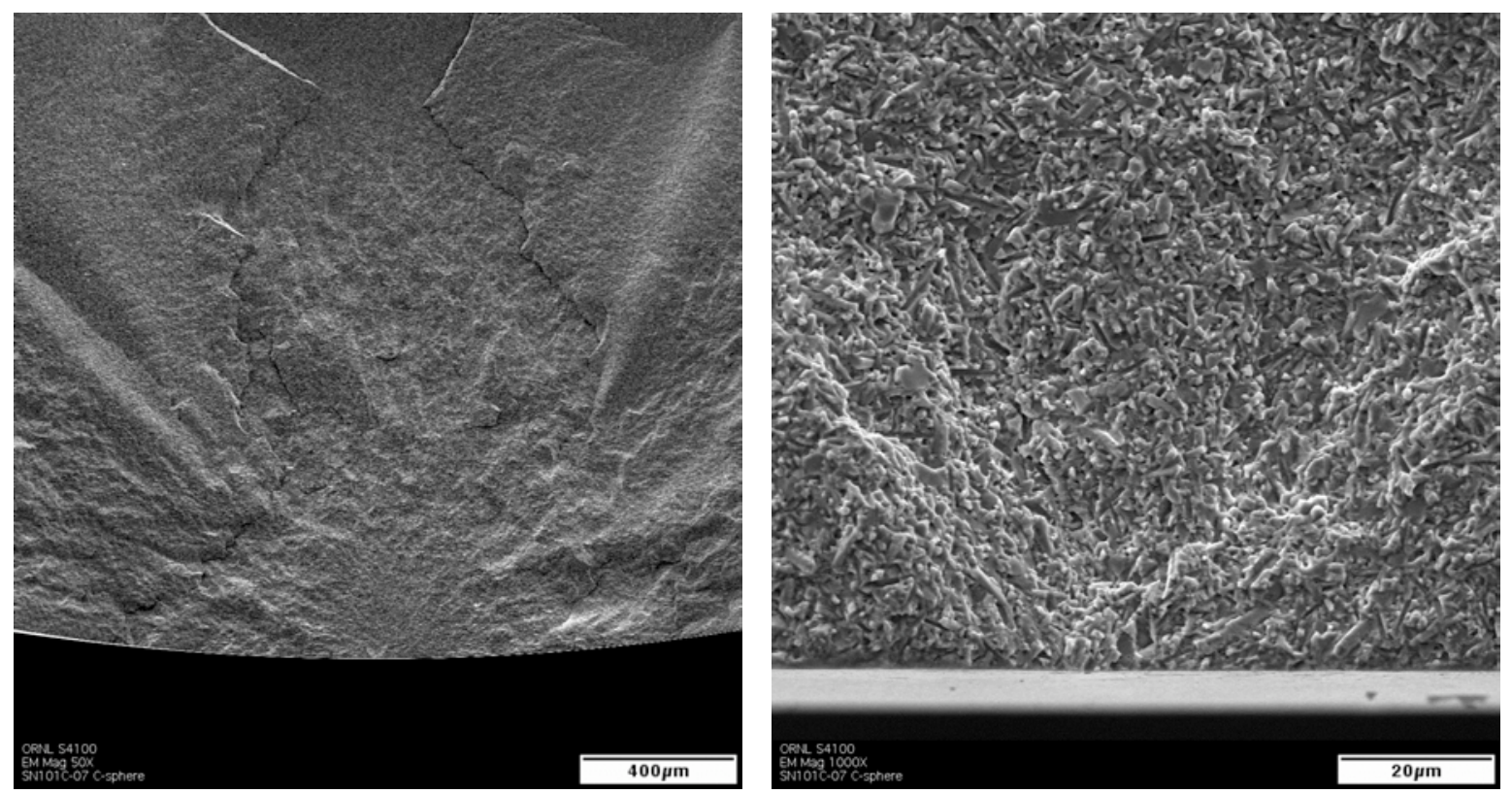

Figure 24. Example of a surface-located strength-limiting flaw in a SN101C C-sphere flexure strength specimen. This specimen had a strength of $770 \mathrm{MPa}$.

\subsubsection{Flaking Fatigue}

At an early stage in the development of ceramic rolling contact bearings, flaking fatigue tests of ceramic balls were carried out using a fatigue test setup for radial contact ball bearings [71]. Six different types of $\mathrm{Si}_{3} \mathrm{~N}_{4}$ were tested and only two of these samples exhibited longer lives than those of steel balls. The flaking fatigue test results are shown in Fig. 25 [71]. Flaking was recognized as the result of crack propagation, either from internal flaws or inclusions. SEM an EDX analysis identified the origin of flaking as the segregation of sintering additives or metallic inclusions during the manufacturing process. 


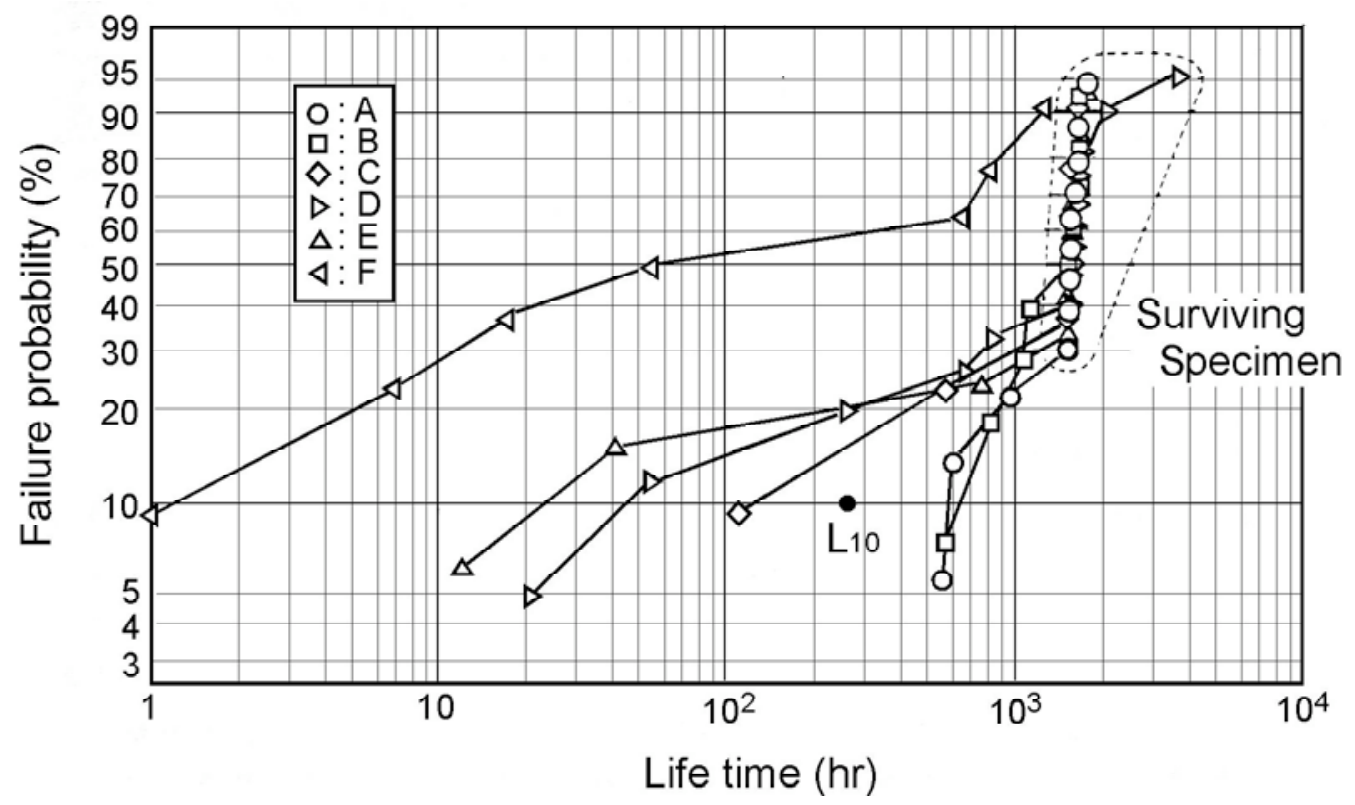

Figure 25. Weibull plots of rolling contact fatigue lifetime.

\subsection{Non-destructive evaluation}

Acoustic methods have widely used in defect characterization of ceramic materials. Scanning acoustic microscopy (SAcM) was employed by Hadfield [66] to quantify incipient delaminated subsurface crack depth. This technique is especially useful for subsurface crack observations of ceramics which are traditionally difficult to experimentally analyze [65]. Scanning acoustic microscopy uses high-frequency acoustic waves to reveal surface topography, subsurface features, and elastic properties of materials. Acoustic waves are produced by a transducer, pass through the coupling liquid (usually distilled water), and reflect from the focal plane (located at a distance ' $z$ ' below the specimen's surface). The reflected acoustic echoes from individual regions are detected during scanning and are used to create images. Compared to optical or electron microscopy, SAcM can penetrate opaque materials to detect subsurface features and localized variations in elastic properties. 
Resonant ultrasound microscopy (RUS) can be used to examine microstructural flaw and surface defects of $\mathrm{Si}_{3} \mathrm{~N}_{4}$ materials. Additionally, elastic properties may be measured with RUS [72] and such results are shown in Fig. 26. Hsieh et al. [73-74] developed the resonant sphere technique to characterize ceramic ball bearing elements, which utilized the surface wave to examine the surface defect population. The resonance quality factor $(\mathrm{Q})$ decreases, in the surface wave mode, due to the existence of surface defects.

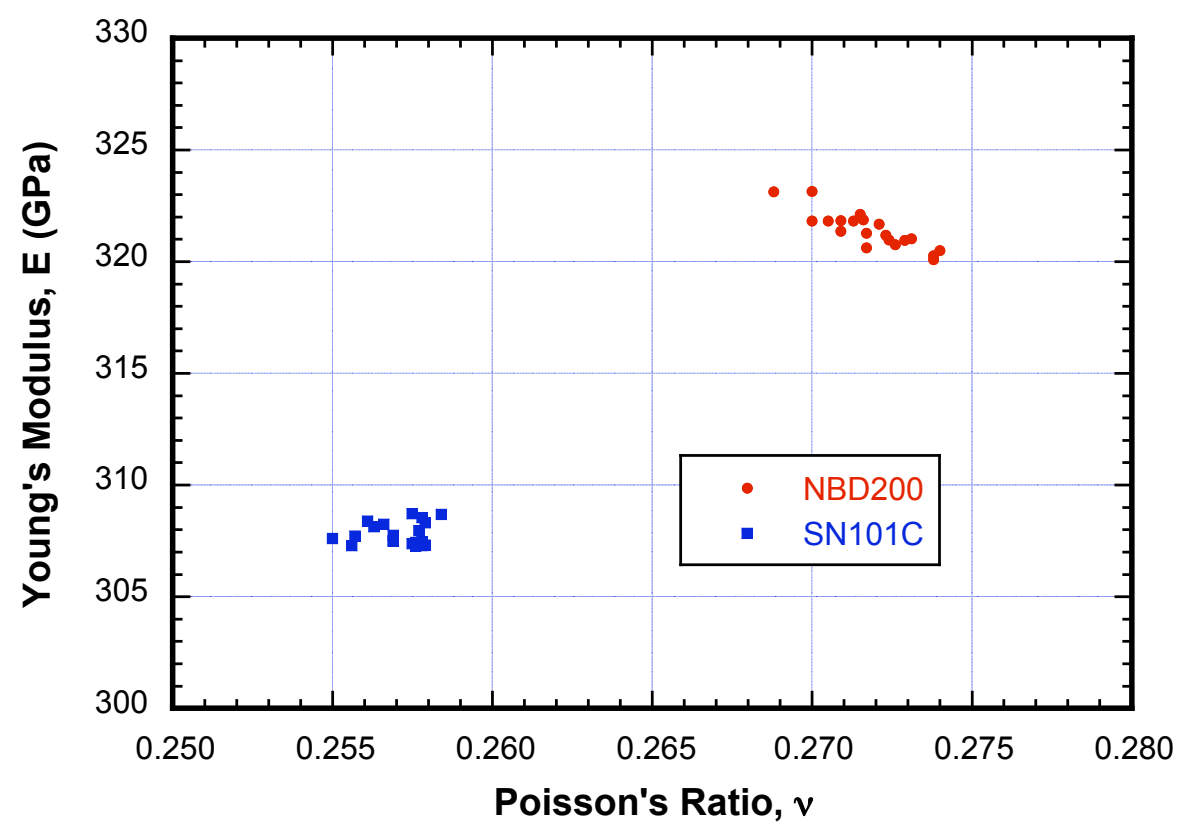

Figure 26. Elastic properties of NBD200 and SN101C balls measured using Resonance Ultrasound Spectroscopy.

A method of locating the position of acoustic emission sources has been applied to identify the position of crack initiation in RCF by Yoshioka et al. [75]. The positions of crack initiation were widely spread and did not always coincide with the theoretical prediction, which assumed that a crack initiates at the depth of the maximum orthogonal shear stress. Further improving the Yoshioka et al. technique may offer the possibility of identifying the onset of crack propagation in a non-destructive manner, leading to higher reliability of rolling bearings in service. 
In addition to the acoustic techniques, the optical coherence tomography (OCT) technique was recently employed by Bashkansky et al. $[76,77]$ to quantify the subsurface defects of $\mathrm{Si}_{3} \mathrm{~N}_{4}$ materials. The results show a great potential to use OCT as a substitute or complement to acoustic techniques.

\section{Summary}

This report surveyed a variety of topics pertaining to RCF of ceramic materials. Surface defects (cracks) in $\mathrm{Si}_{3} \mathrm{~N}_{4}$ and their propagation during RCF were discussed. Five methods to measure RCF were briefly overviewed. Spalling, delamination, and rolling contact wear were discussed. Lastly, methods to destructively (e.g., C-sphere flexure strength testing) and non-destructively identify potential RCF-limiting flaws in $\mathrm{Si}_{3} \mathrm{~N}_{4}$ balls were described.

\section{Acknowledgements}

Research sponsored by the US Department of Energy, Office of FreedomCAR and Vehicle Technologies, as part of the Heavy Vehicle Propulsion System Materials Program, under contract DE-AC-00OR22725 with UT-Battelle, LLC. The authors wish to thank ORNL's P. Blau and J. Qu for their helpful comments.

\section{References}

1. G. Hamburg, P. Cowley, and R. Valori, J. ASME, Lubric. Engrg., 37:407-15 (1981).

2. H. Aramaki, Y. Shoda, Y. Morishita, and T. Sawamoto, J. of Trib., 110:693-8 (1988).

3. B. R. Lawn, J. Am. Cer. Soc., 81:1977-94 (1998).

4. $\quad$ F. C. Roesler, Proc. Phys. Royal Soc. Lond., B69:981-1012 (1956).

5. M. Chaudhri and M. A. Phillips, Phil. Mag., A62:1-27 (1990).

6. M. Ichikawa, T. Takamatsu, T. Matsuo, N. Okabe, and Y. Abe, JSME Intl. J., Series A: Mech. Mat. Engrg., 38:226-30 (1995).

7. K. Ohgushi and M. Ichikawa, JSME Intl. J., Series A: Mech. Mat. Engrg., 38:226-30 (1996). 
8. R. T. Cundill, pp. 556-561 in 6th Intl. Symp. Cer. Mats. Comp. Engines, K. Niihara, S. Kanzaki, K. Komeya, S. Hirano, and K. Morinaga, Eds., Oct. 19-23, 1997, Arita, Japan.

9. $\quad$ F. C. Frank and B. R. Lawn, Proc. Roy. Soc., A299:291-306 (1967).

10. T. R. Wilshaw, 1971. J. Phys. D: Appl. Phys., 4:1567-83 (1971).

11. R. Mouginot and D. Maugis, J. Mater. Sci., 20:4354-76 (1985).

12. B. R. Lawn, Proc. R. Soc. Lond., A299: 307-16 (1967).

13. B. J. Bethune, J. Mater. Sci., 11:199-205 (1971).

14. R. Warren, Acta Metall., 46:1759-69 (1978).

15. Y. Z. Li and D. A. Hills, J. Appl. Mech.-Trans. ASME, 58: 120-7 (1991).

16. P. D. Warren, D. A. Hills, and D. N. Dai, Trib. Intl., 28: 357-62 (1995).

17. N. P. Suh, Wear, 44:1-16 (1977).

18. J. F. Braza, H. S. Cheng, M. E. Fine, A. K. Gangopadhyay, L. M. Keer, and R. E. Worden, Trib. Trans., 32:1-8 (1989).

19. J. R. Fleming and N. P. Suh, Wear, 44:39-56 (1977).

20. D. A. Hills and D. W. Ashelby, Trib. Intl., 12:115-9 (1979).

21. A. R. Rosenfield, Wear, 61:125-32 (1980).

22. L. M. Keer and M. D. Bryant, J. Lubric. Tech.-Trans. ASME, 105:198-205 (1983).

23. M. D. Bryant, G. R. Miller, and L. M. Keer, Q. J. Mech. Apply. Math., 37:468-78 (1984).

24. G. R. Miller, L. M. Keer, and H. S. Cheng, Proc. Roy. Soc. London Series A-Math. Phys. Sci., 397:197-209 (1985).

25. A. F. Bower, J. Trib.-Trans. ASME, 110:704-11 (1988).

26. L. M. Keer and R. E. Worden, Tribol. Trans., 33:411-7 (1990).

27. N. B. Thomsen and B. L. Karihaloo, J. Mech. Phys. Solids, 44:207-31 (1996).

28. H. Tada, P. C. Paris, and G. R. Irwin, Stress Analysis of Cracks Handbook, Paris Publication Inc, St. Louis, MO, 1985.

29. J. C. Newman and I. S. Raju, Computational Methods in the Mechanics of Fracture, North Holland, Amsterdam, 1986.

30. R. O. Ritchie and R. H. Dauskardt, J. Cer. Soc. Japan, 99:1047-62 (1991).

31. R. O. Ritchie, C. J. Gilbert, J. M. McNaney, Intl. J. Solids Struct., 37:311-29 (2000).

32. F. T. Barwell and D. Scott, Engineering, 9-12 (1956).

33. G. S. Krivoshein, Industr. Lub., 26:405-7 (1960). 
34. D. Scott, Study of the Effect of Lubricant on Pitting Failure of Balls, Presented at IMechE, Lub. and Wear Conv., 1963.

35. R. Tourret and E. P. Wright, eds., Rolling Contact Fatigue Performance Testing of Lubricants, presented at the Intl. Symp. of the Instit. of Petroleum, Heydon, London, 1976.

36. A. Scott, J. Blackwell, and P. J. McGullagh, Wear, 17:73-82 (1971).

37. D. Scott and J. Blackwell, Wear, 24:61-7 (1973).

38. M. Hadfield, T. A. Stolarski, and R. T. Cundill, Proc. Royal Soc. London Series A-Math. Phys. Engrg. Sci., 443:607-21 (1993).

39. M. Hadfield, T. A. Stolarski, R. T. Cundill and S. Horton, Trib. Intl., 26:157-64 (1993).

40. M. Hadfield, Cer. Intl., 24:379-86 (1998).

41. T. L. Carter and E. V. Zaretsky, NASA TN D-259, (1960).

42. R. Parker and E. V. Zaretsky, Trans. of the ASME, J. of Lub. Tech., 97:350-7 (1975).

43. T. Fujiwara, T. Yoshioka, T. Kitahara, S. Koizumi, H. Takebayashi, and T. Tada, J. JSLE., 33:301-7 (1988).

44. K. Kikuchi, T. Yoshioka, T. Kitahara, K. Ozaki, K. Nakayama, and T. Fujiwara, J. JSLE Int. Ed., [5] 137-42 (1984).

45. D. Glover, pp. 107-24 in Rolling Contact Fatigue Testing of Bearing Steels, ASTM STP 771, Philadelphia, PA, ASTM, 1982.

46. L. Y. Chao, R. Lakshminarayanan, D. K. Shetty, and R. A. Cutler, J. Am. Cer. Soc., 78:2307-13 (1995).

47. L. Y. Chao, R. Lakshminarayanan, N. Iyer, G. Y. Lin, and D. K. Shetty, Wear, 223:58-65 (1998).

48. R. Lakshminarayanan, L. Y. Chao, N. Iyer, D. K. Shetty, Wear, 210:278-86 (1997).

49. J. W. Lueck, Rolling Wear of Silicon Nitride Bearing Materials, presented at Gas Turbine and Aero-Engine Congress and Expo., Brussels, Belgium, 1990.

50. D. L. Allen, Trib. Trans., 37:410-4 (1994).

51. H. I. Burrier, Trib. Trans., 39:276-85 (1996).

52. Y. Nishihara, NTN Tech. Rev., 54: 31-9 (1998).

53. H. R. Baumgartner, Ed., 1974. pp 713-27 in Evaluation of Roller Bearings Containing HotPressed Silicon Nitride Rolling Elements, Brook Hill Publishing Chestnut Hill, MA. 
54. P. E. Cowley and J. W. Lueck, Investigation of the Use of Silicon Nitride in Aircraft Engine Bearings, Naval Air Systems Command, Contract N00019-76-C-0251, 1979.

55. A. Otsuka, H. Sugawara, M. Shomura, M. Aoyama, S. -K. Yoo, and M. Shibata, J. Soc. Mat. Sci. Japan, 43:55-6 (1994).

56. J. F. Braza, H. S. Cheng, and M. F. Fine, Trib. Trans., 32:439-46 (1989).

57. M. Akazawa and K. Kato, Wear, 124:123-32 (1988).

58. M. Akazawa, K. Kato, and K. Umeya, Wear, 110:285-93 (1989).

59. M. Hadfield and T. A. Stolarski, Trib. Intl., 28:377-82 (1995).

60. F. R. Morrison, J. I. McCool, and T. M. Yonushonis, J. of ASLE, Lubric. Engrg., 40:153-9 (1984).

61. M. Hadfield, T. A. Stolarski, R. T. Cundill, and S. Horton, Wear, 169:69-75 (1993).

62. Y. Wang and M. Hadfield, Wear, 243:157-66 (2000).

63. Y. Wang and M. Hadfield, Wear, 243:167-74 (2000).

64. Y. Wang and M. Hadfield, Wear, 250-251:282-92 (2001).

65. M. Hadfield, S. Tobe, and T. A. Stolarski, Trib. Intl., 27:359-67 (1994).

66. M. Hadfield and T. A. Stolarski, Cer. Intl., 21:125-30 (1995).

67. Test Method for Ultimate Strength of Advanced Ceramics with Diametrally Compressed C-Ring Specimens at Ambient Temperature, C1323-96, ASTM, Conshohocken, PA, 2005.

68. S. S. Kim, K. Kato, K. Hokkirigawa, and H. Abe, Trans. ASME, 108:522-6 (1986).

69. B. A. Kschinka, S. Perrella, H. Nguyen, and R. C. Bradt, J. Am. Cer. Soc., 69, 467-72 (1986).

70. H. Wang and A. A. Wereszczak, Cer. Engrg. Sci. Proc., 26, 275-283 (2005).

71. T. Abe, S. Niizeki, and K. Furumura, pp. 53-6 in Proc. JAST Trib. Conf., Okayama, 1988.

72. A. A. Wereszczak, in press, Cer. Engrg. Sci. Proc. (2006).

73. C. P. Hsieh and B. T. Khuriyakub, Appl. Phys. Lett., 60:1815-7 (1992).

74. C. P. Hsieh and B. T. Khuriyakub, Appl. Phys. Lett., 62:3091-3 (1993).

75. T. Yoshioka and M. Takeda, Lubrication Engrg., 51:41-4 (1994).

76. M. Bashkansky, V. Pujari, J. Reintjes, and H. Y. Yu, NDT\&E Intl., 34:547-55 (2001).

77. M. Bashkansky, M. D. Duncan, M. Kahn, and J. Reintjes, Opt. Lett., 22:61-3 (1997). 